\title{
Improving Volunteer Engagement in Nonprofit Healthcare Organizations
}

\author{
Sanja K. Hudson \\ Walden University, Minneapolis, Minnesota, USA \\ Email: hudsonskh223@gmail.com
}

How to cite this paper: Hudson, S. K. (2021). Improving Volunteer Engagement in Nonprofit Healthcare Organizations. Open Journal of Business and Management, 9, 1367-1408.

https://doi.org/10.4236/ojbm.2021.93074

Received: March 30, 2021

Accepted: May 28, 2021

Published: May 31, 2021

Copyright (อ 2021 by author(s) and Scientific Research Publishing Inc. This work is licensed under the Creative Commons Attribution International License (CC BY 4.0).

http://creativecommons.org/licenses/by/4.0/

(c) (i) Open Access

\begin{abstract}
Grounded in the conceptual lens of Deci and Ryan's self-determination theory, the strategies nonprofit healthcare leaders use to reduce volunteer turnover were explored in this single-case study. The participations included 5 nonprofit healthcare leaders from a single organization in the Southwestern United States. Data were collected using semistructured interviews, internal and external organizational documents, and publicly available data. Analysis of internal and external organizational documents and publicly available data were manually coded and thematically organized. The use of a methodological triangulation process and member checking increased the reliability of data interpretation. Using the thematic approach, 3 themes emerged: volunteer recognition improved volunteer turnover, open communication improved volunteer turnover, and relationship building improved volunteer turnover. The findings from this study may contribute to positively social change by providing nonprofit leaders with strategies to reduce volunteer turnover, enhance operational processes, and improve organizational performance. The results of this study indicated that nonprofit healthcare leaders who develop volunteer engagement strategies could increase organizational success and develop successful work habits among volunteers to improve economic growth in the communities they serve.
\end{abstract}

\section{Keywords}

Competence Behavior, Psychological Needs, Volunteer Engagement

\section{Background and Introduction}

This study is structured by section one: The abstract, purpose statement, the research question, assumptions, limitations, delimitations, and the literature review. In addition, Section two contains the research structure, data collection, 
and analysis. Section three contains the findings, recommendations, and conclusion. In this study, I used the 2017-2018 Baldrige Performance Excellence Framework as a tool to help ensure a holistic, systems-based assessment of an organization (Baldridge Performance Excellence Framework, 2017).

The foundation of the nonprofit world has changed and improving volunteer engagement for increased sustainability is a growing challenge for nonprofit healthcare organizations. Volunteers managed $85 \%$ of charitable nonprofits and contributed 7.97 billion hours of volunteer labor in 2014 (Selcoe, 2016). Guntert and Wehner (2015) noted that leaders understand what motivates volunteers and focused on the individual's experience of autonomy, competence, and relatedness to foster motivation and engagement, increased organizational productivity, and retained volunteers. Oostler, Guntert, Van Schie, Wehner, and Posner (2014) indicated that researchers established a relationship between volunteer engagement, effective leadership, and volunteers' retention. However, research to improve nonprofit organizations' volunteer engagement is minimal ( $\mathrm{McBey}$, Karakowsky, \& Ng, 2017). Only a limited number of researchers have shared volunteer engagement strategies to reduce volunteer turnover in organizations (Newton, Becker, \& Bell, 2014).

Bortree and Waters (2014) suggested increasing volunteer engagement requires nonprofit volunteer leaders that design job tasks around meeting volunteers' needs, resulting in volunteer engagement and increased sustainability. Chiniara and Bentein (2016) proposed leaders that focused less on power-driven and self-interest leadership styles promoted a culture that empowered the individuals, improved performance, and established an environment of trust to motivate individuals. A servant leadership style in organizations reduces employee turnover, empowers volunteers, and increases followers' engagement (Begzadeh \& Nedaei, 2017; Nencini, Romaioli, \& Meneghini, 2016; Palumbo, 2016). Nonprofit organizations must adopt innovative strategies to reduce volunteer turnover rates, enhance operational processes, improve organizational performance, and meet the community's needs with engaged volunteers.

\subsection{Purpose Statement}

The purpose of this qualitative single-case study was to explore strategies nonprofit healthcare leaders use to reduce volunteer turnover. The targeted population comprised five healthcare leaders of a nonprofit organization located in the southwestern United States who had developed strategies to reduce volunteer turnover.

\subsection{Research Question}

The central research question guiding this study was what strategies do nonprofit healthcare leaders use to reduce volunteer turnover? Data derived from semistructured interviews, public documents, and data supplied by the nonprofit healthcare organization's leaders. 


\subsection{Assumptions, Limitations, and Delimitations}

Assumptions are unexamined beliefs subject to critique in the research (Wolgemuth, Hicks, \& Agosto, 2017). In this study, the first assumption I made was that the participants would honestly respond to the research questions. My second assumption was that supporting documentation and data were accessible and accurate. Another assumption was that the participants chosen for this study would offer truthful and unbiased knowledge of the volunteer engagement and turnover characteristics to explore strategies nonprofit healthcare leaders use to reduce volunteer turnover. My final assumption was that using the 2017-2018 Baldrige Performance Excellence Framework and criteria would help ensure a holistic systems-based review of my client organization's strengths and opportunities for improvement (Baldrige Performance Excellence Program, 2017).

Limitations refer to uncontrollable weaknesses researchers postulate during the qualitative study process (Chenail, 2011). The first limitation of this study that I identified was the small sample size. A small sample size may not produce the results needed to answer the research question. The sample size for this single-case study included five healthcare leaders of a nonprofit organization located in the southwestern United States. The second limitation was that participants could withdraw at any time; therefore, participants who finished the study might not have been truly representative of the population. The final limitation of this study was excluding data related to volunteers with less than 1 year of experience in volunteering. The research was dependent on reliable and accurate data from volunteers. Employees who understood the organization's mission and skills needed to contribute to the organization's needs were excluded.

Delimitations help clarify the study's focus by indicating the areas included and excluded to clarify the phenomenon (Barratt, Choi, \& Li, 2011). One delimitation of this study was selecting healthcare leaders with volunteer management knowledge five leaders of a nonprofit healthcare organization in operation for six years in the southwestern United States. The participants' views may not have represented the views of other nonprofit healthcare leaders in other geographical regions of the United States. Another delimitation for this study was researching a nonprofit healthcare organization operated for more than three years and used volunteers to contribute work hours. Other nonprofit healthcare organizations were not included.

\subsection{Significance of the Study}

The results of this study could add value to the practice of business because some nonprofit healthcare leaders lack strategies to reduce volunteer turnover. Engaged volunteers contribute to nonprofit organizations' success and sustainability, reducing the amount of paid working hours, thereby reducing operating costs (Scherer, Allen, \& Harp, 2016; Van Schie, Guntert, \& Wehner, 2014). The findings of this study could be applied by professionals or practitioners to im- 
prove processes for managing volunteers and achieving organizational sustainability.

The results of this study contribute to positive social change by supplying to nonprofit leaders effective strategies to reduce volunteer turnover rates, enhance operational processes, improve overall performance, and meet the needs of the community by engaging volunteers. Nonprofit organizations with knowledge of the strategies and processes that improve volunteer engagement might increase their numbers of volunteers and promote community needs awareness. Communities benefit when volunteers develop successful work habits that can enhance economic growth and continue serving the nonprofit organizations.

The theoretical significance includes Therefore leaders who meet the needs of volunteers might motivate and retain volunteers. Researchers use the SDT to measure the effect of self-determined motivation on volunteer role identity and organization role identity (Guntert \& Wehner, 2015).

\section{A Review of the Academic Literature}

\subsection{Self Determination Theory}

Deci and Ryan's (1985) SDT represents a framework that stipulates individuals require the need for autonomy, competence, and relatedness for psychological growth and well-being. Leaders that understand what engages volunteers and focus on the three constructs associated with SDT increased productivity and retained volunteers (Guntert \& Wehner, 2015). Guntert and Wehner (2015) proposed leaders who recruited volunteers that demonstrated the reason for volunteering associated with SDT created value to meet the organization's needs. Nonprofit healthcare leaders can use the SDT theory constructs to assist with developing a volunteer screening process that identifies the reasons why individuals want to volunteer to improve volunteer recruitment, retention, and engagement. Nonprofit healthcare leaders who fail to meet volunteers' basic psychological needs reduce volunteer engagement and retention (Bidee et al., 2017).

The need for autonomy relates to an individual's choice of flexibility and the freedom to make choices (Nencini et al., 2016). Nonprofit healthcare leaders who allow volunteers to experience ownership of tasks and autonomy of decision-making increase productivity, enhance engagement levels and allow intrinsic motivation to develop (Alfes \& Langner, 2017; Chiniara \& Bentein, 2016; Kang, 2016). Intrinsic motivation refers to behavior driven by an individual's interest, enjoyment, and satisfaction with a task (Bidee et al., 2017). Nonprofit organizations require high levels of intrinsically-motivated workers to meet the organization's social mission when monetary compensation is reduced (DeVaro, Maxwell, \& Morita, 2017).

The need for competence satisfaction refers to individuals' perceived feeling of effectiveness and confidence to achieve favorable outcomes (Chiniara \& Bentein, 2016; Haivas, Hofmans, \& Pepermans, 2014). Nonprofit healthcare leaders that 
implement structured training for volunteers enhance the need to feel efficacy in performing a task while achieving desirable outcomes. Wu, Li, and Khoo, (2016) posited competence satisfaction increased intrinsic motivation, job satisfaction, and volunteers' intention to remain loyal to the organization. To measure the constructs from SDT, nonprofit healthcare leaders can use the Perceived Competence Scale (PCS) to assess volunteers' feelings of competence to complete a task. The PCS is a short questionnaire that evaluates an individual's confidence in a task (Wu et al., 2016).

The need for relatedness reflects the desire to have a secure relationship and a sense of belonging (Reznickova \& Zepeda, 2016). Job performance increases when volunteers maintain a good relationship with other organization members and receive support from staff and other volunteers (Romaioli, Nencini, \& Meneghini, 2016). Volunteers remain committed to nonprofit organizations when they identify with the organization, set boundaries to overcome controlled forms of motivation, perceive a positive image of the organization, and receive guidelines that outline consequences of activities (Romaioli et al., 2016). Although meeting individuals' psychological needs is essential (Guntert \& Wehner, 2015), the benefits justify increasing volunteer engagement and retention strategies.

Suddaby (2015) concluded researchers use theories to organize knowledge and provide valuable information to explain or justify a course of action. I chose the SDT as the conceptual framework for this study because of the validity of when leaders focus on the human needs, values, intrinsic motivation, development, culture motivation, individual differences, and workers psychological well-being performance increases and volunteer turnover decreases (Bidee et al., 2017).

\subsection{Volunteer Management Theory}

The volunteer management theory postulates leaders use the organization's brand heritage to engage and retain volunteers (Curran, Taheri, MacIntosh, \& O'Gorman, 2016). Healthcare leaders may consider using the organization's history and mission through effective marketing to enhance a volunteerism program. Rose, Merchant, Orth, and Horstmann (2016) stipulated that committed individuals relate to an organization's heritage. Some of the reason's individuals volunteer is to give back to the community (Stukas, Hoye, Nicholson, Brown, \& Aisbett, 2014).

Curran et al. (2016) used the volunteer management theory to explore how brand heritage affected volunteer retention, engagement, and satisfaction of active volunteers. Satisfaction with the administration and brand heritage increase levels of engagement for volunteers (Curran et al., 2016). For example, Curran et al. noted a symbolic representation of providing volunteers with uniforms and including them in company activities increased volunteers' participation. Therefore, nonprofit leaders should implement strategies that enhance brand heritage to meet the relatedness needed to demonstrate a sense of value and appreciation for service. 
Nonprofit healthcare leaders can use brand heritage to market to existing and potential volunteers to meet the needs of the organization. Branding of an organization that aligns with culture increases volunteers' and stakeholders' engagement (Curran et al., 2016). Positive brand perception and trust in leadership increase a volunteer's intention to remain loyal to the organization (Coetzer, Bussin, \& Geldenhuys, 2017).

\subsection{Factors Affecting Engagement}

A range of factors affects the reasons volunteers remain engaged and committed to the organization. This section includes factors affecting engagement. The subheadings include studies related to 1) collaboration, 2) communication, 3) feedback, 4) knowledge management, 5) psychological empowerment, 6) training, and (g) trust and transparency. Engaged individuals that find meaning with assignments contribute to the organization and remain loyal (Howell, 2017).

\subsubsection{Collaboration}

Leaders who focus on creating an environment that encourages collaboration, team building, and developing workers' skills may create value for volunteer healthcare organizations. Leaders with a strategy to develop and support individuals who demonstrate the ability to collaborate eliminate the barrier of division among stakeholders (Sanford, 2016). A collaborative approach and input from all healthcare stakeholders, including patients, payers, and providers, provide solutions to the financial solvency of the United States healthcare system (Bosco, Iorio, Barber, Barron, \& Caplan, 2016). Team collaboration amongst individuals inspires relatedness satisfaction, competence satisfaction, and autonomy satisfaction (Bidee et al., 2017).

Corporate leaders that encourage employees to volunteer for nonprofit organizations might increase their social responsibility (Caligiuri \& Thoroughgood, 2015). To increase the corporate organization's reputation, leaders should consider a marketing strategy of collaborating with a nonprofit organization to enhance a volunteerism program. Andriopoulou, Birkos, and Lymberopoulos (2015) researched the benefits of collaboration in the healthcare sector. Data results showed that collaboration with a peer-to-peer approach increased opportunities to share data and eliminated errors with individuals that shared a common interest. Nonprofit healthcare leaders that implement collaboration approaches may increase the relatedness need for volunteers and enhance engagement, retention, and productivity. Nonprofit organizations that collaborate with other organizations decrease duplication of efforts that improve healthcare access to reduce healthcare disparities (Meng, Gull, Ashby, \& Akiko, 2017).

Volunteers are vital in communities with healthcare disparities associated with high palliative care levels (Pesut et al., 2018). The use of volunteers providing navigation support for nonprofit healthcare organizations through collaboration with community leaders and other healthcare stakeholders ensures the 
resolution of the most vulnerable healthcare needs (Pesut et al., 2018). Nonprofit volunteer healthcare organizations with a limit of volunteers to meet the supply and demand of healthcare disparities and medical needs should consider the benefits of implementing a community health workers program. Vareilles, Pommier, Marchal, and Kane (2017) focused on the benefits of community health volunteers (CHVs), to generate positive outcomes to meet healthcare needs in underserved areas. Vareilles et al. explored ways to improve CHVs performance in communities to reduce service gaps in organizations. The researchers noted trained CHVs in underserved areas enhance task sharing strategies and reduce worker shortages.

\subsubsection{Communication}

In the healthcare market focused on quality-of-care outcomes and patient satisfaction, successful communication skills and team collaboration approaches create value for healthcare organizations. Landry and Erwin (2015) found valuable communication skills reduced misunderstandings in healthcare organizations. Nonprofit healthcare leaders that effectively communicate with volunteers may help volunteers achieve increased productivity and inspire innovative thinking. Landry and Erwin (2015) also found drivers that influenced team effectiveness included the quality of team communication, the accuracy of information, the effectiveness of the communication process, and openness in sharing information. Servant leadership enhances communication in the workplace through communicative techniques focused on subordinates' best interests and helping subordinates grow (Abu Bakar \& McCann, 2016). Likewise, Kang (2016) concluded that effective communication with volunteers improved organizations' reputation through positive word-of-mouth marketing techniques. Thus, while Landry and Erwin's findings demonstrated how communication approaches determined individuals' motivation level, Kang showed how ineffective communication with volunteers might damage the reputation of organizations. Management style and precise communication create value to keep workers motivated and engaged (Grujicic, Bata, Radjen, Novakovic, \& Grujicic, 2016).

A range of factors determines volunteer engagement that leaders should consider developing strategies to enhance productivity while understanding the consequences of work engagement. Whiteoak and Mohamed (2016) proposed communication created value to enhance worker engagement. Swensen, Gorringe, Caviness, and Peters (2016) emphasized that culture and operation design increased employee engagement. Van der Walt and Swanepoel (2015) proposed workplace spirituality linked to job involvement enhanced engagement from a distinct perspective. Failure to communicate effectively at all levels of the organization may result in adverse health outcomes and reduce volunteer engagement to meet nonprofit healthcare organizations' organizational goals.

\subsubsection{Feedback}

Nonprofit leaders that acknowledge the value the volunteer brings to the organ- 
ization increase volunteer engagement and retention (Howell, 2017; Soria \& Thomas-Card, 2014). Soria and Thomas-Card (2014) found volunteer students that receive positive feedback on how their contributions created positive community change inherited interest to continue volunteering after graduation. However, Romaioli et al. (2016) emphasized that volunteers remain loyal to nonprofit organizations when they do not anticipate positive feedback from recipients. A serving culture encourages followers or individuals to focus on helping others (Liden, Wayne, Chenwei, \& Meuser, 2014). Developing approaches that recognize volunteers' contributions, providing guidance, and support increases volunteer engagement and retention (Walker, Accadia, \& Costa, 2016). Leaders that satisfy the relatedness need of volunteers through effective feedback, support, and recognition increase engagement and retention (Fallon \& Rice, 2015). Harrison, Xiao, Ott, and Bortree (2017) noted that leaders thanked, and recognized volunteers developed workplace environments of trust, commitment, and satisfaction. A gesture of appreciation or verbally acknowledging the value of a volunteer's contribution to the organization increases volunteer commitment.

\subsubsection{Knowledge Management}

Volunteers that identify with the organization remain loyal (Kang, 2016). Zapata, Cantu, and Mondragon (2016) conducted a study of 28 Monterrey, Mexico nonprofit organizations to identify how knowledge management practices benefit the nonprofit organization. The researchers focused on identifying organizational and personal elements that allowed nonprofit organizations to generate and transfer knowledge to increase sustainability. The results showed knowledge management in Mexican nonprofit organizations provided strategies to enhance the organization's mission, strengthen communication between the organization and stakeholders and increase transparency in operations.

Zapata et al., (2016) suggested effective knowledge transfer strategies required a commitment to the organizations' mission and trust amongst colleagues. Leaders of nonprofit organizations with limited resources to gain knowledge can benefit from Zapata et al., research when developing strategies to engage and retain volunteers through knowledge transfer approaches. Mentoring systems, innovative environment, documentation of processes, and collaboration practices enhance knowledge management (Zapata et al., 2016). From a different perspective, Hume and Hume (2016) examined the value of nonprofit organizations implementing knowledge management strategies to identify gaps in knowledge.

Hume and Hume (2016) proposed the success of a knowledge sharing process that increases skills and innovative thinking require leaders to understand the psychological elements of socialization. In their research, Hume and Hume identified the requirements of a knowledge management process and how leaders can capture and share knowledge within the organization a minimal cost. For example, nonprofit healthcare leaders should consider implementing an in- 
ternal marketing process of volunteers sharing knowledge to provide guidelines to enhance policies and procedures to complete assigned tasks efficiently. Nonprofit healthcare leaders can consider the benefits of implementing knowledge management protocols to increase the autonomy, relatedness, and competence needs of volunteers.

\subsubsection{Psychological Empowerment}

Chen (2016) concluded elderly volunteers learned new or enhanced skills while volunteering to help others. The impact of volunteerism creates opportunities like educating the public about health and safety issues, answering phones at healthcare organizations, providing medical care to patients, or reducing other healthcare disparities in communities. For example, a volunteer health organization might empower volunteers with decision making power regarding outreach to meet the nonprofit organization and community's needs. Sips et al. (2014) posited that leaders who implemented a successful outreach program increased their referral networking to link individuals to the organization.

Paparella-Pitzel, Eubanks, and Kaplan (2016) concluded empowerment helps increase individual self-efficacy and enhances the ability to bring about change in communities. Sheerin, Stonebanks, Jeffery, and Schouten (2016) suggested empowered individuals handle their own beliefs, and organizational change occurs. Therefore, healthcare organizations that seek strategies focused on empowering volunteers and meeting their psychological needs may create value for the individuals, organizations, and communities. Begzadeh and Nedaei (2017) provided information that suggested a servant leadership style that consisted of serving, humility, reliability, kindness, and empowering people created an atmosphere of innovative thinking, increased productivity, and competitive advantage. Begzadeh and Nedaei also suggested organizations that use an empowerment strategy created efficiency, productivity, and a happy working environment.

A psychological empowerment environment creates value in motivation, engagement, and organizational behavior (Ugwu, Onyishi, \& Rodríguez-Sánchez, 2014). Van Winkle, Allen, De Vore, and Winston (2014) concluded servant leaders created innovative thinking environments that empowered followers to do their jobs while increasing knowledge, skills, and productivity. Van et al. also recommended encouraging servant leadership in organizations enhanced the perception of empowerment to motivate and engage workers towards higher levels of work engagement. Supporting Houger (2015) work, Wellens and Jegers (2014) posited the need for nonprofit organizational leaders to develop an effective governance strategy that outlined meeting the needs of volunteers. Thus, creating an environment of innovative thinkers equipped with the necessary empowerment tools and self-determination to succeed may enhance the engagement levels of volunteers, retain loyal volunteers, and increase sustainability for healthcare organizations (Begzadeh \& Nedaei, 2017; Ugwu et al., 2014; Van 
Winkle et al., 2014).

\subsubsection{Training}

Volunteers with confidence in their ability to contribute to the organization and the community remain engaged and loyal to the organization (Harp, Scherer, \& Allen, 2017). Structured training to meet competence satisfaction in a comfortable environment increases loyalty to the organization (Gorski et al., 2017). Bang (2015) encouraged nonprofit organizations to implement training strategies that focused on volunteers' age to increase recruitment and loyalty. Nonprofit leaders who develop and implement training programs that reflect volunteers' needs for different ages might increase volunteerism programs. Tsai and Lin (2014) implied self-improvement training programs increase team collaboration and increase productivity.

Yamashita, López, Soligo, and Keene (2017) researched to explore the motivational factors of older adults' volunteering in urban communities. The study results of 277 middle-aged to older adults concluded creating a learning environment increased volunteer participation and productivity. However, Tang (2016) concluded using social networking of middle-aged and older Americans determined volunteering behavior. Tang suggested organizations interested in recruiting older adults to volunteer focus on individuals at retirement age or recently retired individuals.

Tang (2016) included valuable benefits of recruiting recent or partial retirees to provide the skills and motivation to volunteer their services. Organizations that focus on recruiting retirees that have withdrawn from the work environment for an extended period are less likely to recruit older volunteers. Marketing strategies that focus on collaboration with other stakeholders, adjust to retirement through volunteering, and give back to the community might increase volunteer engagement for older adults (Tang, 2016). Firmin, Luther, Lysaker, and Salyers (2015) provided sufficient evidence that suggested older adults volunteer in healthcare organizations to help those in need, to give back to the community, and to improve medical recovery outcomes for themselves and others. Leaders of nonprofit organizations that identify reasons volunteers offer their services may identify the appropriate task to motivate engaging behavior and recruit needed workers (Firmin et al., 2015). Nonprofit healthcare leaders should consider marketing to older adults with medical licenses to help maintain their licenses and continue using their skills to meet the organization's needs and the community (Chen, 2016; Harp et al., 2017; Tang, 2016).

\subsubsection{Trust and Transparency}

Leaders that enhance organizational trust and psychological empowerment in individuals increase engagement (Ugwu et al., 2014). Harrison et al. (2017) emphasized that volunteers who trusted the organization and worked in environments that encouraged openness continued volunteering. Nonprofit leaders that fail to initiate positive impressions of the organization reduce volunteer reten- 
tion (Carvalho \& Sampaio, 2017). Individuals that feel part of the organization and trust the leaders remain loyal (McGeehan, Takehara, \& Daroszewski, 2017). Rowe and Alexander (2015) suggested environments of transparency and openness increase trust in organizations. Likewise, Block (2016) proposed a strategic plan to enhance recruitment and retention processes through transparency and accountability.

\subsection{Leadership Styles and Engagement}

Leaders that understand and meet the psychological needs of volunteers may sustain the services of the volunteers. Nonprofit leaders struggle to effectively manage and engage millions of volunteers yearly to meet the organization's needs (York, 2017). Nonprofit leaders must adopt innovative strategies and leadership styles to attract and retain volunteers (Hume \& Hume, 2016; Oostlander, Guntert, Van Schie, \& Wehner, 2014; Posner, 2015). This section includes studies on different leadership styles that influence volunteer engagement: 1) ethical, 2) inspirational, 3) servant, 4) transformational, 5) transactional, and 6) participative.

\subsubsection{Ethical Leadership}

Ethical behavior is a necessary component of actual business practice and, therefore, a continuous inquiry and understanding (Jones \& Chin-Yen Alice, 2015). Ethical leadership beliefs include respecting others, serving others, showing justice, manifesting honesty, and building community (Northouse, 2016). Trust and implementing compliance guidelines create value to ensure proper ethical behavior in healthcare organizations. Engelbrecht, Heine, and Mahembe (2017) concluded with questionnaires completed by 204 workers that leaders that encourage and use ethical behavior empower workers to support ethical behavior. Ethical leadership combined with leader integrity enhances relationships between leaders and followers (Engelbrecht et al., 2017).

Northouse (2016) suggested ethical leaders serve others by being altruistic and meeting others' needs for the common good. Management style and precise communication keep employees motivated (Grujicic et al., 2016). Leadership styles focused on teamwork and collaboration may eliminate communication gaps, ensure stakeholders work together to reach a common goal, enhance accountability, and increase ethical behavior. Pozgar (2016) concluded organizations that implement codes of ethics guidelines created environments of trust, awareness of unethical behavior, increased decision-making, and encourage individuals to report instances of misconduct. Further contributing to ethical leadership, Wolin (2016) posited healthcare leaders should eliminate creating unrealistic goals to avoid ethical compliance failure. Nurses assessed high ethics in healthcare organizations reduced emotional work efforts' adverse outcomes and promoted environments to engage workers (Mauno, Ruokolainen, Kinnunen, \& De Bloom, 2016). 


\subsubsection{Inspirational Leadership}

Leadership is a process whereby individuals influence a group of people to achieve a common goal; it is about how individuals work with people to reach a goal (Northouse, 2016; Solomon, Costea, \& Nita, 2016). Bonau (2017) posited inspirational leaders connect with others on an emotional level, the vision they develop is clear, and their communication is effective. Spender (2016) suggested leadership is a way to compensate for failure when management theories fail to develop the managing science. Spender further noted leadership is the practice of attaching a leader's imagination to specific material contexts of human activity.

\subsubsection{Participative Leadership}

Individuals with participative leadership traits encourage collaboration approaches with decision making and autonomous behavior (Alfes \& Langner, 2017). In organizations, leaders that use a participative style reduce the amount of control they have with making decisions (Lam, Wong, \& Tong, 2015). Specifically, participative leaders believe sharing information with workers increases productivity. However, Buengeler, Homan, and Voelpel (2016) posited that a leader's age determined the success of a participative leader. For example, the authors concluded young leaders with limited experience lack the status-related characteristics of experience and competence developed over a period. Researchers that provided an opposing view were Alfes and Langner (2017), who postulated volunteer managers, enhancing volunteers' productivity through a participative leadership style. The authors suggested participative, and directive leadership behavior engages volunteers in nonprofit organizations.

Alfes and Langner (2017) suggested that although volunteers require satisfaction of autonomy, relatedness, and competence, a participative leadership style without direction might increase product-harm to an organization. For example, in nonprofit organizations, volunteers not provided guidance or direction on tasks might reduce organizational outcomes and decrease volunteer engagement. It is, therefore, apparent that nonprofit healthcare leaders cannot focus on a single style that contributes to effective leadership.

\subsubsection{Servant Leadership}

Leadership is critical to all organizations, and preferred leadership styles vary depending on the culture or country (Gahye, Youngsam, Froese, \& Shin, 2016). Thus, the leadership styles in nonprofit organizations staffed with volunteers differ from organizations that pay workers for services performed (Posner, 2015). Servant leadership increases trust, commitment, and empowerment in individuals (Begzadeh \& Nedaei, 2017). Servant leaders use a role model behavior to assist followers in their development and growth (Abu Bakar \& McCann, 2016; Neubert, Hunter, \& Tolentino, 2016). The personality traits in leaders impact the engagement levels of workers (Howell, 2017). Servant leaders possess strong theoretical skills, high levels of honesty, and demonstrate a genuine concern for followers (Liden et al., 2014). A servant leader creates innovative think- 
ing environments that empower followers to perform their tasks while encouraging them to learn and grow (Neubert et al., 2016). Kang (2016) concluded volunteers satisfied with leadership, sense of empowerment, and recognized for contributions to the organization remain engaged and committed to the organization. Furthermore, studies indicate that servant leaders reduce worker burnout and enhance work engagement (Coetzer et al., 2017). Leadership styles that focused on trust, commitment, integrity, and meeting the volunteers' psychological needs increased engagement, productivity and produced innovative thinking environments (Birtch, Chaing, \& Van Esch, 2016; Chiniara \& Bentein, 2016; Kang, 2016; Waters \& Bortree, 2012).

\subsubsection{Transformational Leadership}

Communities benefit from leadership styles that articulate a commitment to the organization's mission and inspire engagement behavior in volunteers (Posner, 2015). Valero, Jung, and Andrew (2015) noted individuals with transformational leadership traits possess innovative, inspirational, and innovative characteristics to meet followers' needs. Mayr (2017) explored the relationship between transformational leadership and volunteer engagement of 213 firefighter volunteers. Mayr noted transformational leaders enhance the workers' intention to continue volunteering. Transformational leadership encourages innovative thinking and personal growth and supports individual coaching and workers' support (Hentrich et al., 2017). Furthermore, Hildenbrand, Sacramento, and Binnewies (2018) noted transformational leadership style reduced burnout and stress levels only for individuals with medium to high levels of open-minded behavior traits. Nonprofit volunteer leaders might benefit from a transformational leadership style when volunteers join the organization with a belief and support of its mission.

Further contributing to transformational leadership, Tung (2016) examined the role of transformational, ambidextrous, and transactional leadership in employee innovation and psychological empowerment. The author concluded that leaders that demonstrate transformational or ambidextrous leadership behaviors have followers that have a higher degree of psychological empowerment. Leaders that possess a transformational trait have workers that seek high degrees of reward for performance (Tung, 2016).

Creativity and innovative thinking improve work environments that encourage openness between leaders and workers (Tung, 2016). Sudha, Shahnawaz, and Farhat (2016) posited a transformational leadership style that included mutual admiration with a shared vision and creative exchange of ideas. Leaders with ambidexterity traits possess the capability to alter styles depending on the circumstance (Kelman, Sanders, \& Pandit, 2016). Ambidextrous leaders use different behaviors when making decisions that affect the organization (Kelman et al., 2016). It is, therefore, apparent that leaders cannot focus on any meticulous or consistent leadership style in determining strategies to engage and retain the services of volunteers to maintain organizational sustainability (Howell, 2017; 
Scherer et al., 2016; Van Schie et al., 2014).

Other notable contributors to the transformational leadership style's development and knowledge include Hawkes, Biggs, and Hergerty (2017). The authors examined the relationship of transformational leadership on resources with a moderating role of recovery experiences. Hawkes et al. hypothesized job resources would mediate the relationship between transformational leadership and engagement. Hawkes et al. determined that recovery experiences did not mediate job resources and engagement. The development of an engaged workforce is the foundation for organizational success. Transformational leadership links to high organizational performance and innovation crucial for the development of engagement. Researchers concluded a definite positive correlation between transformational leadership and engagement (Hawkes et al., 2017; Mayr, 2017).

Hawkes et al. (2017) posited that leaders who demonstrate transformational leadership behaviors link to higher engagement; however, no direct correlation exists between transformational leadership and engagement. Hawkes et al.'s study's implications include a deeper understanding of how transformational leadership behaviors impact workers. When leaders use transformational leadership styles, they use their psychological empowerment to enhance and encourage creativity in workers (Tung, 2016).

\subsubsection{Transactional Leadership}

Transactional leaders provide the resources followers need to complete goals. Buch, Thompson, and Kuvaas (2016) explored the impact leader political skills have on followers' work performance in the transactional leader-member exchange theory. Previous researchers have found a relationship between leader-member exchange quality and follower work performance. The authors found that leader political skills moderated the negative impacts of transactional leader-member exchange. A single downward flow of influence typically defines transactional leader-member exchange relationships (Buch et al., 2016).

Buch et al. (2016) hypothesized a negative relationship between transactional leader-member exchange relationships when a leader restrains follower work performance with high political skill. Transactional leader-member exchange relationships correlated with lowered work performance (Buch et al., 2016). Social leader-member exchange relationships associated with higher work performance. The moderator is the skill of the leader and the variable is the work performance of the follower. The study by Buch et al. provided additional data about the impact of transactional leader-member exchange and followers' behavioral outcomes.

\subsection{The Relationship between Engagement and Sustainability}

In today's healthcare environment, communities' benefit when volunteers develop work habits to improve economic growth and continue serving the organ- 
ization. Volunteerism is a pervasive activity in the United States and 62.6 million people engaged in volunteering in 2016 (Selcoe, 2016). Stukas et al. (2014) implied volunteerism benefits communities with positive outcomes and enhanced volunteers' physical and mental health. Individuals who volunteer for organizations work without pay and make choices to provide services to organizations to help society (Loosemore \& Bridgeman, 2017). Therefore, engaged volunteers help to meet the needs of nonprofit organizations and support continued sustainability.

Conrad, Ghosh, and Isaacson (2015) suggested physicians demonstrated motivated behaviors in environments focused on variety, challenges, and engagement. Grujicic et al. (2016) reported results consistent with Ferreira, Neto, Vasconcelos, and Souki (2016) study. These authors' consistent results indicated that financial incentives do not represent healthcare professionals' fundamental motivational factors. For example, health professionals in urban areas are significantly more motivated than rural health workers (Grujicic et al., 2016). An individual's work location may determine the level of engagement. Alfes, Shantz, and Bailey (2016) defined engagement as a positive and fulfilling work environment with dedicated and active participants that benefit individuals and organizational outcomes.

Leaders who meet the needs of volunteers increase donated hours and accomplish the organization's needs (Scherer et al., 2016). Additionally, McGeehan et al. (2017) provided information that suggested physicians may volunteer their services through marketing focused on volunteering during a discretionary time to eliminate burnout. Herd, Adams-Pope, Bowers, and Sims (2016) suggested healthcare organizations that implemented strategies focused on programs to support future leaders through education and ongoing development created value to address change. For example, independence, reduced administrative duties, and strategies to enhance knowledge may motivate clinical professionals to volunteer and benefit the nonprofit healthcare organization. Thus, understanding workers' psychological needs provides nonprofits with the knowledge to motivate and empower volunteers to increase engagement and productivity.

Chiniara and Bentein (2016) used the autonomous motivational framework of SDT to determine the relationship between a servant leadership style and meeting the psychological needs of workers. Chiniara and Bentein found a positive correlation between a servant leader approach and the three psychological needs of SDT (autonomy, competence, relatedness). A servant leader approach creates increased productivity and positive organizational outcomes (Chiniara \& Bentein, 2016). Likewise, Haivas et al. (2014) proposed organizations implement strategies focused on two types of subpopulations to motivate and engage individuals. For example, one subpopulation focused on tasks with favorable challenges, autonomy, and constant feedback to satisfy independent and competence needs. The second subpopulation focused on fulfilling the relatedness need of individuals through team collaboration. However, Purohit, Maneskar, and Sax- 
ena (2016) concluded job acknowledgment ranked highest to meet psychological needs and motivate individuals towards high productivity. Thus, substantiating individuals are different; what motivates one volunteer towards increased engagement and loyalty depends on the individual's psychological needs.

Various factors link volunteer engagement that leaders should consider when developing strategies to enhance productivity and sustainability. Healthcare organizations focused on implementing strategies to engage volunteers should consider management styles, collaboration techniques, communication approaches, volunteer empowerment, and volunteers' psychological needs to increase motivation and innovative thinking. Ugwu et al. (2014) suggested the leadership style of managers determined the motivation level of individuals. However, Muckaden and Pandya (2016) concluded people inherited the desire to volunteer, possessed a need to help others, received personal growth, and enjoyed volunteering to meet the community's needs.

People volunteer for various reasons, and volunteering plays a vital role in strengthening communities by bridging a gap in healthcare disparities, understanding what motivates individuals to volunteer, and implementing strategies to recruit, retain, and engage volunteers in enhancing teamwork and collaboration in healthcare organizations and the community. Scherer et al. (2016) suggested understanding factors that decreased volunteer engagement created value. In nonprofit healthcare organizations, successful leaders understand that engaging volunteers requires understanding the low motivation cause. For example, healthcare organizations seeking physician volunteers may market to the primary barrier eliminating doctors from volunteering.

Leaders who understand and meet volunteers' psychological needs recruit and retain engaged volunteers (Bidee et al., 2017; Engelbrecht et al., 2017). Healthcare organizations must adopt innovative strategies to engage volunteers. Thus, improving the sustainability of healthcare organizations and meeting the needs of individuals served. Healthcare organizations that focus on innovative approaches create value for patients served, the community, volunteers, and other stakeholders. Nonprofit healthcare leaders must understand traditional ways of providing care to patients for services rendered no longer exist. The various changes in policies and regulations to sustain a competitive edge require implementing effective strategies and engaging all stakeholders.

Additionally, engaged volunteers increase a positive effect on the quality of care for patients, volunteers, and community members. Nonprofit leaders who engage volunteers may create value in the workplace, meet patients' needs, maintain a competitive advantage to reduce healthcare disparities, and increase sustainability. Toader (2014) posited the United States spends more on healthcare than any other developed economy. Alfes and Langner (2017) suggested engaged volunteers increased productivity and sustainability for nonprofit organizations. Therefore, nonprofit healthcare organizations with engaged volunteers help to meet the medical needs of patients and communities. Healthy pa- 
tients can become productive members of society and reduce the cost of healthcare. Nonprofit healthcare leaders that influence the quality of patient satisfaction, engage volunteers, and improve healthcare organizations' professionalism may increase sustainability.

\section{Research Method, Design, Population, Data Techniques, Reliability, and Validity}

By exploring strategies that nonprofit healthcare leaders used to reduce volunteer turnover, this qualitative study's findings provide value to the field. Crane, Henriques, and Husted (2018) noted the appropriate methodology depends on the research question. Researchers use the qualitative research method to explore a phenomenon and obtain a clearer understanding of the underlying reasons and motivations to answer a research question (Crane et al., 2018; Phillippi \& Lauderdale, 2018; Yates \& Leggett, 2016). Qualitative research is a crucial component to understanding lived experiences, bridging gaps, and developing healthcare organizations' strategies (Alderfer, 2017; Lewis, 2015). On the other hand, quantitative research seeks to confirm hypotheses and examine relationships among variables (Barczak, 2015; Christenson \& Gutierrez, 2016; Crane et al., 2018).

I chose a qualitative method because interviews were the primary source to collect data from in this study. Interviews help researchers obtain rich data, provide clarity, and sanction in-depth qualitative analysis (Kenno et al., 2017; Manetti \& Toccafondi, 2014; Rostami, Ashcroft, \& Tully, 2018). The qualitative method was appropriate to collect data and allow for the anonymity needed for individuals to speak openly. Qualitative researchers must consider that in-depth data increases confidence in the study, and the research method provides thorough descriptions of the phenomena (Barczak, 2015; Sousa, 2014). Using a qualitative research method ensured alignment with my research question and provided in-depth data on strategies to reduce volunteer turnover.

I selected a single-case study design for this study. Researchers use a case study design with multiple types of evidence to explore a phenomenon in-depth in real-life settings to produce relevant outcomes (Aulgur, 2016; Loosemore \& Bridgeman, 2017; Yin, 2018). The qualitative, single-case study design allowed me to focus on the strategies nonprofit healthcare leaders implemented to reduce volunteer turnover. Ridder (2017) stated that a single-case study design allowed detailed descriptions and analysis to understand how and why things happen. When collecting information from in-depth interviews, the case study design allowed participants to communicate and explain their perceptions of volunteer turnover strategies.

Researchers use open-ended questions to gather information in qualitative research (Lewis, 2015). In the semistructured interviews with participants, I asked open-ended questions to stay focused on and obtain clarity from their responses (Kenno, McCracken, \& Salterio, 2017). Open-ended questions allowed the study 
participants to provide more in-depth responses to the questions and reach data saturation (Tran, Porcher, Tran, \& Ravaud, 2017).

\subsection{Population and Sampling}

The population and group mix for this single-case study included the president, board member, directors, and a manager. This study included a purposeful sampling method consisting of five nonprofit healthcare organization leaders in operation for 6 years in the southwestern United States. Qualitative researchers use purposeful sampling to obtain rich data related to the phenomenon studied when limited resources exist (Benoot, Hannes, \& Bilsen, 2016; Palinkas et al., 2015). Duan, Bhaumik, Palinkas, and Hoagwood (2014) stated that purposeful sampling identifies common patterns to formulate and evaluate assumptions.

Boddy (2016) suggested a method did not exist to enumerate the appropriate sample size for a qualitative study, but sampling until data saturation reached justifies the size. In a case study, saturation occurs when selecting participants or the data examined does not lead to new information and themes (Boddy, 2016; Palinkas et al., 2015; Valeau, 2015). I reviewed the data to determine if saturation occurred within the first three participants. The data did not provide sufficient evidence that saturation occurred; therefore, I interviewed two more participants until no new information and themes occurred (Tran et al., 2017). When data and information gathered from semistructured interviews and documents reviewed revealed no further information, I achieved data saturation.

The participants for this study had to meet the eligibility criteria of being leaders of a nonprofit healthcare organization in the southwestern United States and agree to participate in an interview by providing their consent. Diversity in the participants provided a rich quality of data from different leadership levels within the organization. The assigned client leader ensured I received the signed informed consent agreements to interview the participants via e-mail.

The semistructured interviews consisted of open-ended questions that lasted around 60 minutes over the telephone. Using open-ended questions allowed participants to reflect on their familiarity and provide more in-depth and new insights on the subject (Lewis, 2015; Loosemore \& Bridgeman, 2017). All participants answered the same questions but allowed follow-up questions to probe for unique insights. I aligned the interview questions with the 2017-2018 Baldrige Performance Excellence Framework to ensure coverage of all areas (Baldrige Performance Excellence Program, 2017). Methodological triangulation was used to analyze the participants' data, documents gathered to study the phenomenon, and achieve data saturation (Lorhan, van der Westhuizen, \& Gossmann, 2015). The information gathered was grouped into individual themes that expressed a coherent idea. I used an Excel spreadsheet to track themes from the interviews. The themes aligned with $\mathrm{ABC}$ Company's operational challenges related to volunteer turnover.

To collect rich and thick data, I conducted an organizational assessment of 
$\mathrm{ABC}$ Company and factors that impacted volunteer turnover. The data types included but were not limited to: financial statements, patient demographic documents, ABC Company website, board minutes, promotional material for volunteers and stakeholders, volunteer orientation documents, and public competitor data. The analysis of the collected data determined the effectiveness and efficiency of leadership and organizational sustainability.

\subsection{Data Collection Instruments}

In qualitative research, the researcher is often the primary instrument for data collection (Fusch \& Ness, 2015; Van den Berg \& Struwig, 2017). I served as the primary data collection instrument in this qualitative single case study. Fusch and Ness, (2015) posited that researchers collect data using different qualitative research methods, including interviews or focus group discussions. I used semistructured interviews, public documents, and data supplied by the nonprofit healthcare organization's leaders. The research questions and objectives determine methods to gather data and efficiently use it (Fusch \& Ness, 2015).

I used the 2017-2018 Baldrige Performance Excellence Framework and criteria to collect the data from the nonprofit healthcare organization's five leaders (Baldrige Performance Excellence Program, 2017). The semistructured interviews provided insight on the strategies nonprofit healthcare leaders used to reduce volunteer turnover. Semistructured interviews facilitate opportunities to obtain information, provide clarity, and help the researcher stay focus (Kenno et al., 2017; Manetti \& Toccafondi, 2014). Romaioli et al. (2016) found semistructured interviews in a study on volunteer commitment allowed participants to attribute meaning to their voluntary work. Interviews with the five nonprofit healthcare leaders include eight open-ended interview questions and started with an interview protocol. Leaders participated in 30 to 45 -minute interviews. However, up to 60 minutes allowed additional time to gather the leader's perceptions or experiences. With the participants' permission, I audio-recorded the interviews, transcribed, and de-identified them with a member checking process to ensure the accuracy of information gathered.

Researchers use member checking as part of the data collection process to check for dialogues' accuracy and eliminate misrepresentation (Debono et al, 2017; Thomas, 2017; Varpio et al., 2017). Therefore, using member checking involved inviting the research participants to review, comment on, and contribute additional information that enhanced the study's reliability and validity. To clarify statements, confirm the accuracy of semistructured interview transcriptions, clarify public documents and data supplied by the research participants, I used member checking. Methodological triangulation supported understanding the unmet needs and resolutions, analyzing the data, achieving data saturation, and increasing the case study's validity (Lorhan et al., 2015). Last, I provided the client leader with a copy of this doctoral study to review and approve before publication. 


\subsection{Data Collections Techniques}

Upon receiving IRB approval, I began the data collection process to explore strategies nonprofit healthcare leaders use to reduce volunteer turnover. Semistructured interviews with five leaders, reviewing internal and external public documents on $\mathrm{ABC}$, and analyzing known competitors supported the data collection technique. Qualitative researchers use purposeful sampling to identify participants, obtain rich data related to the phenomenon studied, and identify common patterns to evaluate assumptions (Benoot et al., 2016; Duan et al., 2014; Palinkas et al., 2015).

The semistructured interviews included overarching interview questions drawn from historical literature, and the research question focused on nonprofit healthcare leader's strategies to reduce volunteer turnover. The participants responded to eight open-ended interview questions following the interview protocol. Researchers use open-ended questions to explore the different aspects of a concept from research participants and to obtain clarity (Kenno et al., 2017; Lewis, 2015; Tran et al., 2017). The semistructured interviews provided in-depth knowledge and new ideas focused on enhancing the understanding of the phenomenon.

The internal and external documents included background information, competitor information, and federal nonprofit organizational requirements to support this qualitative single-case study's validity and reliability. Internal documents included bylaws, board minutes, financial reports, volunteer promotional material, and volunteer orientation-documents. External documents included the corporate website, performance outcomes data from the nonprofit database GuideStar and Free Clinics Federal Tort Claims Act (FTCA) Program Policy Guide (2014). To prevent data collection problems, researchers should follow specific practices to collect the data (Sheehan, 2018). A member checking process provided leaders of $\mathrm{ABC}$ Company the opportunity to validate their responses to the semistructured interviews and the accuracy of internal and external data analyzed for the study.

\subsection{Data Organization Techniques}

To stay organized, I created a file-naming system to keep track of electronic data, maintained a journal of conversations and thoughts, and stored all hard copies in a locked file in my home office. Hua, Jiang, Zhu, Feng, and Xu (2014) suggested that researchers create an innovative process to organize data provide ease and efficiency to access data. I used pseudonyms for the participants, and a fictional name for the organization studied to ensure confidentiality. Separate secured files for each participant contained the transcribed interview audio taping notes, the informed consent form, and the transcribed journal notes. The secured electronic file entitled ABC Company contained data collected on the organization. I used Microsoft Office products on a Windows operating system to manage the data and a thumb drive stored in a locked file. 


\subsection{Data Analysis}

Researchers use a qualitative data analysis process to discover new ideas and increase the understanding of the phenomenon (Fusch \& Ness, 2015). Fusch and Ness (2015) also posited the first process of data analysis included identifying raw data. Fusch and Ness (2015) concluded that methodological triangulation ensures rich in-depth data to understand a phenomenon. To analyze raw data from multiple sources and study strategies nonprofit healthcare leaders use to reduce volunteer turnover, I used methodological triangulation. Lorhan et al. (2015) concluded researchers use methodological triangulation to collect data to study the phenomenon, analyze the data, and achieve data saturation.

In this study, by interviewing five leaders of a nonprofit healthcare organization and collecting internal and external documents, I understood the phenomenon. The data collected and transcripts generated raw data. A coding process using Microsoft Excel software, a cost-effective method, uncovered patterns and overriding themes. I reviewed and combined the codes into themes to explore what strategies $\mathrm{ABC}$ leaders used to reduce volunteer turnover. Researchers select a coding process to identify and create themes from transcripts and organize and highlight meaning to code qualitative data (Kroll, 2017; Vaughn \& Turner, 2016). Themes in qualitative studies describe information related to the foundation of the study (Wieland, Handfield, \& Durach, 2016). During the coding process, I remained aware of my personal bias and open to new information due to my 20 years of experience working for nonprofit healthcare organizations. My experience working for nonprofit healthcare organizations was a considerable asset to data collection and analysis. After the coding process and analyzing the data collected, to ensure reliability, member checking validated the interpretation of the themes.

To explore strategies nonprofit healthcare leaders, use to reduce volunteer turnover, I used the SDT. Deci and Ryan's (1985) theory suggests leaders that focus on the human needs, values, intrinsic motivation, development, culture motivation, individual differences, and psychological well-being of workers enhance performance. I correlated key themes with studies focused on three constructs underlying the SDT conceptual framework competence, autonomy, and relatedness.

\subsection{Reliability and Validity}

Qualitative researchers implement methods to ensure reliability, credibility, transferability, and confirmability (Abdalla, Oliveira, Azevedo, \& Gonzalez, 2018). East (2016) suggested bias increases when a researcher finds it challenging to measure the study's quality. Researchers establish reliability in qualitative studies to enhance consistency in the research methods and findings and minimize bias and errors (Yin, 2018). Noble and Smith (2015) declared that incorporating methodological strategies in qualitative research increases the study's reliability. 
Reliability for this study began with a purposeful sampling method to obtain rich data related to the phenomenon. Triangulation and member checking ensured data dependability. Houghton, Casey, Shaw, and Murphy (2013) suggested using several methods to obtain triangulation enhanced credibility to improve the validity and reliability of the research study. Triangulation helped with bias, document data quality, and maximized confidence in the qualitative study's findings. Fusch and Ness (2015) suggested getting data triangulation created a means to data saturation.

I improved the data dependability of this study by increasing the amount of literature reviewed to verify emergent theorizing, triangulating across multiple sources of data, and regularly debriefing participants on interpretations. Member checking ensures the accuracy of data collected, increases validity, and establishes trust in the research process (Chen, 2016; Debono et al., 2017; Thomas, 2017; Varpio et al., 2017). Member checking in this study allowed participants to ensure interpretations made sense in the context of their lived experience on strategies to reduce volunteer turnover.

\subsection{Validity}

This study aimed to explore reliable and valid processes and data that mitigate the chance of bias and misinterpretation. Smith and Noble (2014) noted that bias in research decreases the study's validity and reliability. Researchers who collect data from multiple sources increase their study's validity and reduce bias (Chiniara \& Bentein, 2016; Starr, 2014). To establish validity, I used triangulation and member checking to verify this study's accuracy and credibility. Fusch and Ness (2015) revealed researchers who fail to reach data saturation impact the quality and validity of their research study.

Houghton et al. (2013) concluded researchers achieve credibility through prolonged engagement, triangulation, peer debriefing, and member checking. Rowe and Alexander (2015) suggested researchers increase credibility in their study through transparency, openness, clarity, peer review, and reproducing results of other studies. Credibility correlates to trust, and researchers that fail to obtain trust develop studies of false knowledge (Rowe \& Alexander, 2015). I enhanced credibility by integrating member checking, using methodological triangulation, and using an interview protocol. Manetti and Toccafondi (2014) posited that researchers' fail to engage stakeholders reduced the study findings' credibility. Throughout the research process, I engaged in feedback and clarification from ABC's leaders to enhance credibility.

To ensure this study is conducted in a rigorous manner, another criterion to consider is confirmability to support the results. Noble and Smith (2015) concluded that addressing truth value, consistency, and applicability achieve confirmability. In this study, the strategies used to ensure confirmability included triangulation, member checking, and maintaining an audit trail. To eliminate bias, I collected data from multiple sources, used an interview protocol, tran- 
scribed notes from the interviews, and allowed $\mathrm{ABC}$ leaders to validate my findings (Chiniara \& Bentein, 2016; Debono et al., 2017; Starr, 2014).

Kroll (2017) noted researchers achieve trustworthiness of a qualitative study when others can transfer the findings to other contexts or settings. Cavalcanti (2017) concluded researchers use different approaches to facilitate transferability. For example, in this research study, using purposeful sampling, member sampling, and collecting in-depth data enhanced trustworthiness and transferability. Purposeful sampling identifies common patterns to formulate and evaluate assumptions (Duan et al., 2014). Transparency and detailed descriptions of study participants, framework, and location enhance transferability in a qualitative study (Cavalcanti, 2017). Providing detailed information about the researcher's role, participants, research method and design, ethical practices, data collection instruments and techniques, data organization, and data analysis allows readers and future researchers to determine my findings' transferability.

\section{Findings and Results}

\subsection{Product and Process Results}

$\mathrm{ABC}$ leaders operate the nonprofit healthcare clinic three days a week with $100 \%$ volunteer workers. The leaders of $\mathrm{ABC}$ opened the clinic in 2012 with a goal to reduce healthcare disparities and improve health outcomes for individuals with low or no income. Since ABC's nonprofit ruling year in 2014, ABC's leaders have met the medical needs of more than 400 individuals that lack legal status or cannot afford health insurance. In 2016, the leaders of ABC saw 450 active patients that averaged 3.82 visits per individual. In 2018 from May through July, leaders provided medical services to 501 active patients averaging 1.58 visits per individual. During this study, ABC company switched EMR systems. The lack of a succession plan to protect archived data prevented leaders from extracting data from the old EMR system for FY2017 and FY2018 (January-April).

The public health department that started in March 2018 conducts health education classes and support groups to support the organization's mission. Participant 1 noted space constraints, scheduling conflicts, and lack of patient buy-in contribute to the low participation average of 2.6 patients per month for the diabetic support group. $\mathrm{ABC}$ leaders advertise and sell $\mathrm{t}$-shirts and mugs to market the organization's services and offset the cost to operate the organization. Leaders of $A B C$ acknowledge a breakdown number of $t$-shirts and mugs sold does not exist.

\subsubsection{Customer Results}

The leaders of $A B C$ acknowledged a formal process of determining patient satisfaction, dissatisfaction, and engagement does not exist. Leaders of $\mathrm{ABC}$ plan to implement formal processes in 2019 and use volunteers from the community to serve as health promoters to conduct patient surveys. The information from the surveys will promote opportunities to obtain actionable information and in- 
crease patient engagement.

\subsubsection{Workforce Results}

Changes in the leadership at $\mathrm{ABC}$ resulted in a new president, board chair, and board members with a goal to improve volunteer engagement, capability, and capacity. All participants interviewed suggested a hostile working environment as a critical reason volunteers left the organization. The ABC leaders use a student clinical rotation program to provide professional development of students. They plan to implement formal protocols to encourage volunteer participation at the end of the clinical rotation. All study participants noted a system does not exist to learn more about students' long-term goals to continue volunteering at the end of clinical rotations or practicums. Data received from ABC leaders indicate more than $95 \%$ of the volunteers at the organization represent students.

In 2018, ABC leaders designed a promotion to bring awareness of volunteer needs and recruit additional volunteers to meet the needs of patients served. ABC leaders used the organization's social media account for a volunteer promotion. The promotion ran for about three days to recruit physicians, nurses, physician assistants, nurse practitioners, and volunteers. The promotion achieved 2577 views, was shared by 12 individuals, and created a network of individuals, with $\mathrm{ABC}$ receiving 26 messages from potential volunteers.

\subsubsection{Leadership and Governance Results}

The absence of a strategic plan may limit leaders' ability to empower the community and reduce healthcare disparities. The leadership of ABC consists of elected board members appointed in 2018 and 12 core volunteers. Participant 2 noted core volunteers spend 10 hours to over 20 hours a week at the clinic or demonstrate their dedication to the mission through their service longevity. One individual represents $8 \%$ of the core volunteers serving more than 30 hours a week. Six individuals represent $50 \%$ of the core volunteers serving 1 - 3 years; three individuals represent $25 \%$ of the core volunteers serving 3 - 5 years. Two individuals represent $17 \%$ of core volunteers serving about six and a half years.

All participants noted to improve volunteer engagement transparency, two-way communication, meeting the needs of volunteers, and ensuring a favorable working environment exists with the new leadership. Participants further acknowledged a formal tracking system does not exist to determine if new approaches demonstrate favorable outcomes to engage volunteers. Participant 4 noted efforts to increase the percentage of nonstudent volunteers from $2 \%$ might provide opportunities to track volunteer engagement. Participant 1 noted $98 \%$ of volunteers only volunteer to get required student hours. Therefore, after the student and clinic relationship and no efforts to learn more about long-term goals, $\mathrm{ABC}$ 's leaders lose opportunities to increase volunteer engagement.

To increase societal responsibilities and support key communities, ABC's leaders use a social media website to engage volunteers and other stakeholders. The social media website provides information on needs and accomplishments 
within the organization. Additionally, leaders of $A B C$ use the website and social media site to recognize volunteers. Leaders of $A B C$ noted the social media site provides opportunities to increase a sense of belonging by recognizing volunteers' hard work and increasing volunteer engagement. The social media site depicts a reduction in daily total reached, engaged, and viral reach users for March 2018, May 2018, and July 2018. The first half of August 2018 shows a significant increase in the number of unique people engaged with $\mathrm{ABC}$ leader's social media post.

\subsubsection{Financial and Market Results}

Leaders of $\mathrm{ABC}$ operate the company with limited financial resources from donors. In 2016, ABC's leaders secured a one-time grant and increased individual financial contributions to increase assets between 2015 and 2016. Although $A B C$ 's leaders show a deficit in expenses to revenue in 2017 of $\$ 34,173$, the carryover revenue from past years indicates a positive cash balance over $\$ 90,000$ at the end of 2017. Revenue at $\mathrm{ABC}$ represents $21 \%$ of free clinics operating with revenue between $\$ 0$ and $\$ 100,000$.

\subsubsection{Key Themes}

Process strengths. ABC leader's process strengths included meeting the psychological needs of volunteers through two-way communication and recognizing the volunteer workforce's efforts to promote the MVV's of ABC. Fallon and Rice (2015) posited that leaders recognize workers increase engagement and retention. Lam et al. (2015) noted that leaders use two-way communication and implement training strategies to allow the workforce to understand their roles, expectations and increases participation. Additional process strengths for $\mathrm{ABC}$ leaders include using social media platforms and a website to market to potential volunteers and inform stakeholders of weekly events.

Another process strength to emerge was the volunteer application process to determine the critical drivers of volunteer engagement and training. Lack of training reduces volunteers' commitment to remain loyal to the organization (Kappelides, 2017). Monthly BOD and workforce meetings and encouraging an environment of trust, knowledge sharing, and collaboration emerged as additional process strengths for $\mathrm{ABC}$ leaders. The leaders of $\mathrm{ABC}$ also use a safety-net networking approach with other organizations to eliminate duplication of services. The networking allows $\mathrm{ABC}$ leaders to refer patients to other organizations and exchange information to meet the needs of the uninsured or working poor.

\subsection{Process Opportunities}

After analysis of semistructured interviews, financial statements, patient demographic documents, $\mathrm{ABC}$ Company website, board minutes, promotional material for volunteers and stakeholders, and volunteer orientation, emergent themes for process opportunities to improve are 1) strategic planning with mea- 
surable goals; 2) customization and formal training of volunteer software management system; 3) developing a formal survey or process to determine patient satisfaction, dissatisfaction, and engagement; 4) a systematic approach to determine critical drivers of volunteer satisfaction, dissatisfaction, and engagement; 5) enhance website accessibility; 6) develop succession planning strategies; and

7) BOD orientation and training.

The absence of a systematic approach to strategic planning may limit leaders' ability to collaborate effectively with organizations committed to social justice to achieve shared goals and objectives. The leaders of ABC use a crisis management approach to handle threats aimed at harming the organization's sustainability. Implementing a formal strategic plan provides opportunities to clarify priorities and guide decisions to enhance sustainability where limited financial resources exist (Brosan \& Levin, 2017). Although ABC leaders implemented a volunteer software system that allows volunteers the flexibility of scheduling their volunteer hours, Participant 4 noted the lack of training to retrieve statistical data on volunteers exists.

A formal process of determining patient satisfaction, dissatisfaction, and engagement may allow the leaders of $\mathrm{ABC}$ the opportunity to determine if their efforts to meet the needs of medically marginalized people with respect and dignity exist. Additionally, no implementation of patient satisfaction, dissatisfaction, and engagement data reduces opportunities to determine positive community growth and education to foster self-reliance. Lorhan et al. (2015) suggested engaged volunteers enhance a favorable experience for patients. Another process opportunity identified for improvement exists with understanding the satisfaction and dissatisfaction with volunteers at ABC company. All participants of this study noted a formal process of recording reasons volunteers leave the organization, and long-term goals of student volunteers do not exist. Developing a formal process for determining volunteer satisfaction and dissatisfaction through an exit interview protocol may provide $\mathrm{ABC}$ leaders with strategies to improve volunteer engagement.

Though $98 \%$ of the patients serviced at ABC speak Spanish, a gap exists between the $2 \%$ that speak English. For example, the ABC website structure only advertises upcoming groups available to patients and other stakeholders who follow Spanish, therefore, reducing opportunities to engage non-Spanish speaking people. Jorde Bloom and Abel (2015) posited organizations expand leadership through a leadership succession plan to ensure the sustainability of a program. The absence of a succession planning strategy to eliminate gaps in leadership when critical BODs and other essential workers of volunteer depart the organization may increase worker burnout and reduce engaged volunteers. The ABC leaders can implement a succession plan to recruit BODs and other critical volunteers to ensure volunteers are developed continuously to handle worker gaps within the organization.

The skills-based BOD at ABC Company is accountable for the organization's 
policies and responsible for assisting the president with meeting the MVV via specific specifications in the bylaws. Although the BOD chair discussed strategies to engage BODs, implementing a formal BOD orientation and training does not exist. The leaders of $\mathrm{ABC}$ can initiate formal orientation, training, and an annual board retreat to increase accountability and develop a clear plan on the organization's direction with measurable goals to maintain sustainability.

\subsection{Results Strengths}

A result strength of $\mathrm{ABC}$ leaders included increasing the number of active patients requiring medical services. Although the patient visits and visits per patient declined, data indicates the attention to primary medical healthcare needs requires fewer clinic visits. A review of data on peer-support groups supports the core competency and MVV of ABC leaders to meet people's healthcare needs with limited or no resources to maintain healthy lives, demonstrating a commitment to societal well-being. Leaders of $\mathrm{ABC}$ used the sales of $\mathrm{t}$-shirts and mugs to offset operation costs. In 2015, an increase in community events contributed to the rise in sales. Though the data reviewed depicts a decline in sales from 2015 to 2016, leaders increased sales in 2017.

A review of $\mathrm{ABC}$ companies' social media platform provided insight into people's engagement by gender, viral distribution of the leader's post, and success with bringing awareness of the MVV and needs of the organization. Additionally, the increase in lifetime unique users helped $\mathrm{ABC}$ leaders promote brand heritage and reveal their commitment to demonstrating the volunteer workforce's value and appreciation. The breakdown of active volunteers for FY2017 to August 2018 depicts a commitment to recruit volunteers. The leaders of ABC increased student volunteers in 2018 from 74 volunteers in January 2018 to 109 volunteers in August. Additionally, nonstudent volunteers increased from four volunteers in January 2018 to six in August.

The $\mathrm{ABC}$ president, lab director, and social media coordinator celebrated about seven years of volunteer service to meet medically marginalized people's needs in 2018. Finally, ABC's leaders increased assets and revenue from 2014 to 2017. Although a decline in revenue existed between 2016 and 2017, data depicts a favorable cash flow of over $\$ 90,000$ for 2017.

\subsection{Results Opportunities}

Although $\mathrm{ABC}$ leaders increased the number of active patients and reduced patient visits, leaders need to strategize on opportunities to increase available clinic hours and available clinic space. Participant 1 noted the available space and clinic design allow for limited volunteers. Therefore, reducing the number of medically marginalized people requiring assistance. To increase volunteer engagement, leaders of ABC should consider modifying the operation design. Swensen et al. (2016) noted culture and operation design increased engagement in the workplace. 
Leaders of $A B C$ should increase patient buy-in of the peer-support groups available to medically marginalized people. Firmin, et al. (2015) suggested understanding the disparities of targeted participants may increase peer-support group involvement. In 2017, ABC's leaders increased sales of t-shirts and mugs, but no data exist on the actual number of items sold. The leaders of $\mathrm{ABC}$ could implement a tracking procedure to capture items in stock, actual items sold and modify financial reports to show trends in profit and loss.

Social media outcomes show ABC leader's ability to engage stakeholders. Though the clinic only operates on Thursdays, Fridays, and Saturday's opportunities exist to increase stakeholder engagement on Sundays, Mondays, Tuesdays, and Wednesdays. Leaders can schedule posts for the social media account ahead of time to increase site engagement and increase the number of potential volunteers. According to $A B C$ 's active volunteer results, leaders of $A B C$ increased student and nonstudent volunteers in 2018. Leaders of ABC should consider implementing strategies to increase nonstudent volunteers and processes to encourage student volunteers to remain at the end of course assignments. All the study participants noted a formal system of learning long-term goals of student volunteers and implementing change might increase volunteer engagement. Finally, $A B C$ leaders' financial results show the organization operates with minimal resources. Leaders of $\mathrm{ABC}$ should consider increasing funding from grants and creating an appreciation process to recognize donors. Pressrove and Pardun (2016) suggested nonprofit organizations focused on building loyal relationships increased financial sustainability. Leaders of $\mathrm{ABC}$ have impressive social media engagement results. The leaders should adopt effective social media strategies to reach out to potential donors.

\section{Summary, Findings, Recommendations, and Conclusion}

Various factors link stakeholders to organizations that leaders should consider when implementing strategies to enhance a volunteer nonprofit organization's productivity and sustainability. Overcoming the challenges of volunteer recruitment and engagement in nonprofit organizations is critical for sustainability. Selcoe (2016) posited that volunteers manage $85 \%$ of charitable nonprofits and contributed 7.97 billion hours of volunteer labor in 2014. Therefore, nonprofit leaders who understand what motivates individuals to volunteer and focus on their experience of autonomy, competence, and relatedness will, as Guntert and Wehner (2015) noted, retain volunteers.

In this study, I analyzed various engagement strategies leaders of $A B C$ use to secure donated hours from a volunteer workforce. Leaders' ability to maintain an environment of respect and dignity was critical to engage volunteers and increase sustainability. Kumnig et al. (2015) posited a positive correlation between meeting individual psychological needs and future participation. Understanding volunteers' psychological needs increases engagement and sustainability of a volunteer workforce. 
Participants in this study provided valuable information for short- and long-term action plans and insight on areas requiring improvement to engage volunteers. This study provided evidence requiring leaders to implement policies and procedures, strategic planning, funding strategies, and board engagement. Additionally, the data analyzed provided knowledge of leadership, strategy, customers, measurement, analysis, knowledge management, workforce, and operations for a volunteer-run nonprofit primary care clinic located in the southwestern United States. Leaders of other nonprofit organizations that rely on the volunteer workforce for sustainability may benefit from the strategies and recommendations identified in this study to recruit, engage, and retain volunteers. The implication for social change from the findings of this study includes the potential to contribute to nonprofit leaders' effective strategies to reduce volunteer turnover, enhance operational processes, improve overall performance, and meet the community's needs by engaging volunteers.

\subsection{Contributions and Recommendations}

Nonprofit leaders rely heavily on volunteers, but most nonprofit healthcare leaders lack strategies to reduce volunteer turnover. Recruiting, engaging, and retaining volunteers can lead to empowering the community and reduction in healthcare disparities. Engaging the exemplary volunteers and developing a strategic approach to managing the volunteer workforce can fill operational process gaps and increase donated hours for long periods. This study provided $A B C$ leaders with strategies to catalyze volunteer engagement and meet medically marginalized people's needs. Based on the data analyzed, $\mathrm{ABC}$ leaders operating with limited financial resources meet the needs of more than 500 active medically marginalized people with more than 100 volunteers.

Implementing a formal strategic plan with measurable goals provides leaders of $A B C$ opportunities to enhance sustainability and enhance volunteer engagement. I recommend $\mathrm{ABC}$ leaders follow through on plans for an annual $\mathrm{BOD}$ and core volunteers retreat. Additionally, I recommend $A B C$ leaders implement formal training of BODs that outline the specific roles and responsibilities to serve on the $A B C$ board. Interviews with $A B C$ leaders and review of internal documents revealed a lack of training of BODs to encourage engagement. Therefore, reducing opportunities to fulfill accountability requirements for the organization's policies and assisting the president with meeting the MVV.

Leaders of $A B C$ use effective methods through social media accounts and volunteer appreciation events to engage, motivate and maintain good relationships with workers. It is my recommendation that leaders of $A B C$ implement a formal PCS questionnaire to access volunteers' feelings of competence. The PCS questionnaire used by $\mathrm{ABC}$ leaders can provide valuable information to implement needed policies, procedures and enhance volunteer engagement through perceived feelings of effectiveness and confidence to complete tasks. Additionally, implementing the volunteer management software system's formal training will 
provide $\mathrm{ABC}$ leaders with valuable statistical data on the volunteers. For example, knowing the types of individuals that volunteer at the organization; sex, age, education level, retiree stage, may provide leaders of $\mathrm{ABC}$ with a marketing strategy to increase volunteers.

Developing a formal process to determine patient satisfaction, dissatisfaction, and engagement provides $\mathrm{ABC}$ leaders with another opportunity to close gaps in healthcare disparities. Leaders of $\mathrm{ABC}$ are encouraged to work with community members to identify and train volunteer health promoters to conduct one-on-one surveys with patients. Attendance at community events and working with other community stakeholders provides leaders of $\mathrm{ABC}$ with opportunities to promote and implement a health promoter team capable of analyzing and understanding the needs of patients serviced at the organization, further supporting the MVV of the organization.

Although $\mathrm{ABC}$ leaders implemented processes to engage volunteers through open communication, formal processes to record reasons individuals volunteer and stop volunteering for the organization provide essential data for volunteer workforce engagement, recruitment, and retention. Leaders of $\mathrm{ABC}$ can create and implement quarterly volunteer engagement satisfaction and dissatisfaction questionnaires along with the open communication strategy. Creating an exit interview process for volunteers that stop volunteering provides leaders of $A B C$ with answers to reasons individuals stop volunteering at the organization. The leaders of $\mathrm{ABC}$ can initiate the exit interviews when an individual provides verbal notification of intent to stop volunteering or through e-mail if the volunteer stops volunteering at the organization without providing notification.

Another recommendation for $\mathrm{ABC}$ leaders focuses on the need to increase space and clinic design. The $\mathrm{ABC}$ leaders noted regrouping and rebuilding the nonprofit, developing the public health program, and recruiting volunteer providers as short-term action plans. Space restraints and patient buy-in of services offered through the public health program reduce opportunities for growth. $\mathrm{ABC}$ leaders operate the clinic three days a week. To increase participation and meet the needs of the community, I recommend $\mathrm{ABC}$ leaders consider changing the design of the public health education program to operate on the available nonclinic days. Additionally, public health education leaders should develop a referral strategy process to engage volunteer providers. For example, recognition strategies for volunteer providers that refer and follow-through the process to ensure patient buy-in of available resources offered through the public health program to reduce healthcare disparities.

Leaders of $A B C$ increased the number of volunteers donating hours to meet the MVV of the nonprofit organization. Most $\mathrm{ABC}$ volunteers represent students required to complete course hours with no intentions of remaining after-course assignments. Therefore, creating an operation strain with limited hours to consistently train new volunteers. I recommend $\mathrm{ABC}$ leaders enhance processes aimed to make the students' experiences positive to bring awareness to 
positive change within the community, reduce healthcare disparities, and share the vision of the clinic to increase their willingness to volunteer at the end of the clinical rotation practicum. Additionally, I recommend leaders of ABC implement strategies to increase processes to encourage nonstudents to volunteer. The $\mathrm{ABC}$ leaders could partner with the local Chamber of Commerce, the County Board of Supervisors, Census Bureau division, and other key stakeholders to identify new residents to the community. A cost-efficient and straightforward process of sending a welcome to the community postcard that outlines the MVV of $\mathrm{ABC}$ Company may increase volunteer intrinsic motivation among new and existing residents.

Leaders of $\mathrm{ABC}$ operate with minimal funding to meet the needs of more than 500 patients. I recommend the leaders of $\mathrm{ABC}$ increase funding opportunities through grants and increased donations. Volunteers at $\mathrm{ABC}$ Company receive no financial compensation for donated hours. Strategies to respect volunteers' flexibility and freedom when volunteering to help $A B C$ leaders meet volunteers' autonomy needs. However, through increased funding, ABC's leaders could increase outreach events, expand on volunteer appreciation events, and optimize the organization's layout and design. I recommend $\mathrm{ABC}$ leaders adopt complex financial management systems, including detailed records of t-shirts, mugs, and additional donated items to offset operations' costs.

Researchers who review my research may benefit from strategies identified and recommendations for nonprofit leaders who rely on the services of donated volunteer hours for sustainability. Future research can focus on engagement factors in-depth by exploring the role of age and gender in volunteering amongst volunteers in nonprofit organizations. Conducting a case study design with multiple nonprofit organizations may provide additional information on strategies leaders use to reduce volunteer turnover. I recommend future researchers use numerous nonprofit organizations' qualitative and quantitative research methods to identify different strategies for increasing volunteer engagement. Future studies can also benefit from examining volunteers and managers of a volunteer workforce in other geographical regions with more than 3 years of service.

\subsection{Conclusion}

In this study, I incorporated a purposeful sampling method to recruit five nonprofit healthcare organizations located in the southwestern United States. To gain an understanding of the operations and identify gaps in processes and procedures, I gathered data from semistructured interviews with the five leaders, reviewed internal and external public documents, social media platforms, and analyzed known 501(c)(3), free medical clinics in the client service area. Data collected and analyzed resulted in the identification of four themes: process strengths, process opportunities, results strengths, and results opportunities.

I provided leaders of the client organization with recommendations to improve volunteer engagement and recruitment, enhance policies and procedures, 
and improve the overall performance of operations to meet the community's needs. The results of this study supported the need for nonprofit and for-profit leaders who rely on a volunteer workforce for sustainability to understand the psychological needs of individuals donating hours. The client organization leaders operate with a $100 \%$ volunteer workforce and rely on donations for sustainability, so understanding how to recruit, engage, and retain volunteers is imperative to the organization's sustainability.

\subsection{Recommendations}

The results of this study are evidence of the reasons leaders should develop and implement effective strategies to engage their volunteer workforce. The contributions to business practice include the data analyzed and information learned to improve managing volunteers and achieving organizational sustainability. Social change contributions include the client organization learning additional sstrategies and processes that enhance volunteer engagement and reduce healthcare disparities to empower the community.

My recommendations for future implementation include BOD succession planning to set the protocols for board engagement and performance, creation and implementation of onboarding training for new board members, review and revision of job descriptions of all board members and leaders of the organization to establish accountability, the elimination of conflicts of interest and burnout of the president and board chair by separating the roles, and the identification of opportunities to participate in community events to market the needs of the organization. Furthermore, my recommendations include implementing an active recruitment and retention program for nonstudent volunteers, developing a stewardship section on the website and social media account to appeal to both one-time donors and recurring donors, and resolving complaints quickly.

\section{Conflicts of Interest}

The author declares no conflicts of interest regarding the publication of this paper.

\section{References}

Abdalla, M., Oliveira, L., Azevedo, C., \& Gonzalez, R. (2018). Quality in Qualitative Organizational Research: Types of Triangulation as a Methodological Alternative. Administração: Ensino E Pesquisa, 19, 66-98. https://doi.org/10.13058/raep.2018.v19n1.578

Abu Bakar, H., \& McCann, R. (2016). The Mediating Effect of Leader-Member Dyadic Communication Style Agreement on the Relationship between Servant Leadership and Group-Level Organizational Citizenship Behavior. Management Communication Quarterly, 30, 32-58. https://doi.org/10.1177/0893318915601162

Alderfer, M. (2017). Introduction to Special Issue: Improving Clinical Practices in Pediatric Psychology through Qualitative Research. Clinical Practice in Pediatric Psychology, 5, 299-302. https://doi.org/10.1037/cpp0000222

Alfes, K., \& Langner, N. (2017). Paradoxical Leadership. Organizational Dynamics, 46, 
96-103. https://doi.org/10.1016/j.orgdyn.2017.04.005

Alfes, K., Shantz, A., \& Bailey, C. (2016). Enhancing Volunteer Engagement to Achieve Desirable Outcomes: What Can Non-Profit Employers Do? VOLUNTAS: International Journal of Voluntary \& Nonprofit Organizations, 27, 595-617. https://doi.org/10.1007/s11266-015-9601-3

Andriopoulou, F., Birkos, K., \& Lymberopoulos, D. (2015). P2Care: A Dynamic Peer-to-Peer Network for Collaboration in Personalized Healthcare Service Delivery. Computers in Industry, 69, 45-60. https://doi.org/10.1016/j.compind.2014.09.007

Aulgur, J. (2016). Governance and Board Member Identity in an Emerging Nonprofit Organization. Administrative Issues Journal: Education, Practice, and Research, 6, 6-21. https://doi.org/10.5929/2016.6.1.1

Baldrige Performance Excellence Program. (2017). 2017-2018 Baldrige Excellence Framework: A Systems Approach to Improving Your Organization's Performance. Gaithersburg, MD: U.S. Department of Commerce, National Institute of Standards and Technology. https://www.nist.gov/baldrige/2017-2018-baldrige-excellence-framework

Bang, H. (2015). Volunteer Age, Job Satisfaction, and Intention to stay: A Case of Nonprofit Sport Organizations. Leadership \& Organization Development Journal, 36, 161-176. https://doi.org/10.1108/LODJ-04-2013-0052

Barczak, G. (2015). Publishing Qualitative versus Quantitative Research. Journal of Product Innovation Management, 32, 658. https://doi.org/10.1111/jpim.12277

Barratt, M., Choi, T. Y., \& Li, M. (2011). Qualitative Case Studies in Operations Management: Trends, Research Outcomes, and Future Research Implications. Journal of Operations Management, 29, 329-342. https://doi.org/10.1016/j.jom.2010.06.002

Begzadeh, S., \& Nedaei, M. (2017). The Relationship between Servant Leadership with Organizational Trust and Employee Empowerment in the Social Security Organization of Ardabil. International Journal of Management, Accounting \& Economics, 4, 270-281.

Benoot, C., Hannes, K., \& Bilsen, J. (2016). The Use of Purposeful Sampling in a Qualitative Evidence Synthesis: A Worked Example on Sexual Adjustment to a Cancer Trajectory. BMC Medical Research Methodology, 16, Article No. 12. https://doi.org/10.1186/s12874-016-0114-6

Bidee, J., Vantilborgh, T., Pepermans, R., Willems, J., Jegers, M., \& Hofmans, J. (2017). Daily Motivation of Volunteers in Healthcare Organizations: Relating Team Inclusion and Intrinsic Motivation Using Self-Determination Theory. European Journal of Work \& Organizational Psychology, 26, 325-336. https://doi.org/10.1080/1359432X.2016.1277206

Birtch, T. A., Chiang, F. F., \& Van Esch, E. (2016). A Social Exchange Theory Framework for Understanding the Job Characteristics-Job Outcomes Relationship: The Mediating Role of Psychological Contract Fulfillment. International Journal of Human Resource Management, 27, 1217-1236. https://doi.org/10.1080/09585192.2015.1069752

Block, D. J. (2016). Understanding Recruitment and Retention. Physician Leadership Journal, 3, 44-47. https://www.physicianleaders.org/publications/journal

Boddy, C. R. (2016). Sample Size for Qualitative Research. Qualitative Market Research: An International Journal, 19, 426-432. https://doi.org/10.1108/QMR-06-2016-0053

Bonau, S. (2017). How to Become an Inspirational Leader, and What to Avoid. Journal of Management Development, 36, 614-625. https://doi.org/10.1108/JMD-03-2015-0047

Bortree, D. S., \& Waters, R. D. (2014). Race and Inclusion in Volunteerism: Using Communication Theory to Improve Volunteer Retention. Journal of Public Relations Re- 
search, 26, 215-234. https://doi.org/10.1080/1062726X.2013.864245

Bosco, J., Iorio, R., Barber, T., Barron, C., \& Caplan, A. (2016). Ethics of the Physician's Role in Health-Care Cost Control: AOA Critical Issues. Journal of Bone \& Joint Surgery, 98, Article No. e58. https://doi.org/10.2106/JBJS.15.00889

Brosan, D., \& Levin, M. (2017). Strategic Planning in the Nonprofit World: What Does It Look Like? OD Practitioner, 49, 67-69. https://www.isodc.org/

Buch, R., Thompson, G., \& Kuvaas, B. (2016). Transactional Leader-Member Exchange Relationships and Follower's Work Performance: The Moderating Role of Leaders' Political Skill. Journal of Leadership \& Organizational Studies, 23, 456-466. https://doi.org/10.1177/1548051816630227

Buengeler, C., Homan, A., \& Voelpel, S. (2016). The Challenge of Being a Young Manager: The Effects of Contingent reward and Participative Leadership on Team-Level Turnover Depend on Leader Age. Journal of Organizational Behavior, 37, 1224-1245. https://doi.org/10.1002/job.2101

Caligiuri, P., \& Thoroughgood, C. (2015). Developing Responsible Global Leaders through Corporate-Sponsored International Volunteerism Programs. Organizational Dynamics, 44, 138-145. https://doi.org/10.1016/j.orgdyn.2015.02.008

Carvalho, A., \& Sampaio, M. (2017). Volunteer Management beyond Prescribed Best Practice: A Case Study of Portuguese Non-Profits. Personnel Review, 46, 410-428. https://doi.org/10.1108/PR-04-2014-0081

Cavalcanti, M. (2017). Guidelines for Qualitative Research in Organization Studies: Controversy and Possibilities. Administration: Teaching and Research, 18, 457-488. https://doi.org/10.13058/raep.2017.v18n3.522

Chen, L. (2016). Benefits and Dynamics of Learning Gained through Volunteering: A Qualitative Exploration Guided by Seniors' Self-Defined Successful Aging. Educational Gerontology, 42, 220-230. https://doi.org/10.1080/03601277.2015.1108150

Chenail, R. (2011). Interviewing the Investigator: Strategies for Addressing Instrumentation and Researcher Bias Concerns in Qualitative Research. The Qualitative Report, 16, 255-262.

Chiniara, M., \& Bentein, K. (2016). Linking Servant Leadership to Individual Performance: Differentiating the Mediating Role of Autonomy, Competence and Relatedness Need Satisfaction. The Leadership Quarterly, 27, 124-141. https://doi.org/10.1016/j.leaqua.2015.08.004

Christenson, J., \& Gutierrez, D. (2016). Using Qualitative, Quantitative, and Mixed Methods Research to Promote Family Therapy with Adolescents in Residential Settings. Contemporary Family Therapy: An International Journal, 38, 52-61.

https://doi.org/10.1007/s10591-016-9374-x

Coetzer, M., Bussin, M., \& Geldenhuys, M. (2017). The Functions of a Servant Leader. Administrative Sciences, 7, Article No. 5. https://doi.org/10.3390/admsci7010005

Conrad, D., Ghosh, A., \& Isaacson, M. (2015). Employee Motivation Factors. International Journal of Public Leadership, 11, 92-106.

https://doi.org/10.1108/IJPL-01-2015-0005

Crane, A., Henriques, I., \& Husted, B. (2018). Quants and Poets: Advancing Methods and Methodologies in Business and Society Research. Business \& Society, 57, 3-25. https://doi.org/10.1177/0007650317718129

Curran, R., Taheri, B., MacIntosh, R., \& O’Gorman, K. (2016). Nonprofit Brand Heritage: Its Ability to Influence Volunteer Retention, Engagement, and Satisfaction. Nonprofit 
and Voluntary Sector Quarterly, 45, 1234-1257. https://doi.org/10.1177/0899764016633532

Debono, D., Greenfield, D., Testa, L., Mumford, V., Hogden, A., Pawsey, M., \& Braithwaite, J. (2017). Understanding Stakeholders' Perspectives and Experiences of General Practice Accreditation. Health Policy, 121, 816-822.

https://doi.org/10.1016/j.healthpol.2017.05.006

Deci, E. L., \& Ryan, R. M. (1985). The General Causality Orientations Scale: Self Determination in Personality. Journal of Research in Personality, 19, 109-134. https://doi.org/10.1016/0092-6566(85)90023-6

DeVaro, J., Maxwell, N., \& Morita, H. (2017). Training and Intrinsic Motivation in Nonprofit and For-Profit Organizations. Journal of Economic Behavior \& Organization, 139, 196-213. https://doi.org/10.1016/j.jebo.2017.04.005

Duan, N., Bhaumik, D., Palinkas, L., \& Hoagwood, K. (2014). Optimal Design and Purposeful Sampling: Complementary Methodologies for Implementation Research. Administration and Policy in Mental Health and Mental Health Services Research, 42, 524-532. https://doi.org/10.1007/s10488-014-0596-7

East, R. (2016). Bias in the Evaluation of Research Methods. Marketing Theory, 16, 219-231. https://doi.org/10.1177/1470593115609797

Engelbrecht, A., Heine, G., \& Mahembe, B. (2017). Integrity, Ethical Leadership, Trust and Work Engagement. Leadership \& Organization Development Journal, 38, 368-379. https://doi.org/10.1108/LODJ-11-2015-0237

Fallon, B., \& Rice, S. (2015). Investment in Staff Development within an Emergency Services Organisation: Comparing Future Intention of Volunteers and Paid Employees. The International Journal of Human Resource Management, 26, 485-500. https://doi.org/10.1080/09585192.2011.561222

Ferreira, C., Neto, M., Vasconcelos, F., \& Souki, G. (2016). Motivation and Rewards to Health Professionals. Revista Gestão \& Planejamento, 17, 41-58.

Firmin, R., Luther, L., Lysaker, P., \& Salyers, M. (2015). Self-Initiated Helping Behaviors and Recovery in Severe Mental Illness: Implications for Work, Volunteerism, and Peer Support. Psychiatric Rehabilitation Journal, 38, 336-341. https://doi.org/10.1037/prj0000145

Fusch, P., \& Ness, L. (2015). Are We There Yet? Data Saturation in Qualitative Research. The Qualitative Report, 20, 1408-1416.

https://cpb-us-east-1-juc1ugur1qwqqqo4.stackpathdns.com/sites.nova.edu/dist/a/4/file s/2015/09/fusch1.pdf

Gahye, H., Youngsam, C., Froese, F., \& Shin, M. (2016). The Effect of Leadership Styles, Rank, and Seniority on Affective Organizational Commitment: A comparative study of U.S. and Korean employees. Cross Cultural \& Strategic Management, 23, 340-362. https://doi.org/10.1108/CCSM-03-2014-0034

Gorski, H., Gull, B., Harris, T., Garfield, T., Ashby, J., \& Akiko, K. (2017). Volunteer Experiences at a Free Clinic in the United States: A Qualitative Study. Diversity \& Equality in Health \& Care, 14, 130-135. https://doi.org/10.21767/2049-5471.1000103

Grujicic, M., Bata, J., Radjen, S., Novakovic, B., \& Grujicic, S. (2016). Work Motivation and Job Satisfaction of Health Workers in Urban and Rural Areas. Vojnosanitetski Pregled: Military Medical \& Pharmaceutical Journal of Serbia, 73, 735-743. https://doi.org/10.2298/VSP140715062G

Guntert, S., \& Wehner, T. (2015). The Impact of Self-Determined Motivation on Volunteer Role Identities: A Cross-Lagged Panel Study. Personality \& Individual Differences, 
78, 14-18. https://doi.org/10.1016/j.paid.2015.01.017

Haivas, S., Hofmans, J., \& Pepermans, R. (2014). “What Motivates You Doesn't Motivate Me": Individual Differences in the Needs Satisfaction-Motivation Relationship of Romanian Volunteers. Applied Psychology: An International Review, 63, 326-343. https://doi.org/10.1111/j.1464-0597.2012.00525.x

Harp, E., Scherer, L., \& Allen, J. (2017). Volunteer Engagement and Retention. Nonprofit \& Voluntary Sector Quarterly, 46, 442-458. https://doi.org/10.1177/0899764016651335

Harrison, V., Xiao, A., Ott, H., \& Bortree, D. (2017). Calling All Volunteers: The Role of Stewardship and Involvement in Volunteer-Organization Relationships. Public Relations Review, 43, 872-881. https://doi.org/10.1080/00223980.2017.1372339

Hawkes, A., Biggs, A., \& Hergerty, E. (2017). Work Engagement: Investigating the Role of Transformational Leadership, Job Resources, and Recovery. The Journal of Psychology, 151, 509-531. https://doi.org/10.1080/00223980.2017.1372339

Hentrich, S., Zimber, A., Garbade, S., Gregersen, S., Nienhaus, A., \& Petermann, F. (2017). Relationships between Transformational Leadership and Health: The Mediating Role of Perceived Job Demands and Occupational Self-Efficacy. International Journal of Stress Management, 24, 34-61. https://doi.org/10.1037/str0000027

Herd, A., Adams-Pope, B., Bowers, A., \& Sims, B. (2016). Finding What Works: Leadership Competencies for the Changing Healthcare Environment. Journal of Leadership Education, 15, 217-233. https://doi.org/10.12806/V15/I4/C2

Hildenbrand, K., Sacramento, C., \& Binnewies, C. (2018). Transformational Leadership and Burnout: The Role of Thriving and Followers' Openness to Experience. Journal of Occupational Health Psychology, 23, 31-43. https://doi.org/10.1037/ocp0000051

Houger, V. (2015). How Program Design Affects Program Performance and Participant Motivation. Performance Improvement, 54, 10-18. https://doi.org/10.1002/pfi.21492

Houghton, C., Casey, D., Shaw, D., \& Murphy, K. (2013). Rigour in Qualitative Case-Study Research. Nurse Researcher, 20, 12-17.

Howell, A. (2017). Engagement Starts at the Top: The Role of a Leader's Personality on Employee Engagement. Strategic HR Review, 16, 144-146.

https://doi.org/10.1108/SHR-03-2017-0017

Hua, Y., Jiang, H., Zhu, Y., Feng, D., \& Xu, L. (2014). Sane: Semantic-Aware Name Space in Ultra-Large-Scale File Systems. IEEE Transactions on Parallel \& Distributed Systems, 25, 1328-1338. https://doi.org/10.1109/TPDS.2013.140

Hume, C., \& Hume, M. (2016). What about Us? Exploring Small to Medium Australian Not For-Profit Firms and Knowledge Management. Journal of Knowledge Management, 20, 104-124. https://doi.org/10.1108/JKM-12-2014-0497

Jones, K., \& Chin-Yen Alice, L. (2015). Ethical Decision Making: A Model Demonstrating Collectivism and Individualism Decision Influences. Academy of Business Research Journal, 3, 74-82. http://www.academyofbusinessresearch.com

Jorde Bloom, P., \& Abel, M. (2015). Expanding the Lens-Leadership as an Organizational Asset. YC: Young Children, 70, 10-17. http://www.naeyc.org

Kang, M. J. (2016). Moderating Effects of Identification on Volunteer Engagement. An Exploratory Study of a Faith-Based Charity Organization. Journal of Communication Management, 20, 102-117. https://doi.org/10.1108/JCOM-08-2014-0051

Kappelides, P. (2017). Camp Based Volunteers: Psychological Contracts and Intentions to Volunteer. World Leisure Journal, 59, 79-85.

https://doi.org/10.1080/16078055.2017.1393882 
Kelman, S., Sanders, R., \& Pandit, G. (2016). I Won't Back Down? Complexity and Courage in Government Executive Decision Making. Public Administration Review, 76, 465-471. https://doi.org/10.1111/puar.12476

Kenno, S., McCracken, S., \& Salterio, S. (2017). Financial Reporting Interview-Based Research: A Field Research Primer with an Illustrative Example. Behavioral Research in Accounting, 29, 77-102. https://doi.org/10.2308/bria-51648

Kroll, J. (2017). Requisite Participant Characteristics for Effective Peer Group Mentoring. Mentoring \& Tutoring: Partnership in Learning, 25, 78-96. https://doi.org/10.1080/13611267.2017.1308096

Kumnig, M., Schnitzer, M., Beck, T., Mitmansgruber, H., Jowsey, S., Kopp, M., \& Rumpold, G. (2015). Approach and Avoidance Motivations Predict Psychological Well-Being and Affectivity of Volunteers at the Innsbruck 2008 Winter Special Olympics. VOLUNTAS: International Journal of Voluntary \& Nonprofit Organizations, 26, 801-822. https://doi.org/10.1007/s11266-014-9462-1

Lam, L., Wong, A., \& Tong, C. (2015). The Relationships between Knowledge Transfer, Knowledge Dissemination Capability and Inter-Organizational Dynamics in Public and Private Sectors Organizations. British Journal of Economics, Management \& Trade, 10, 1-17. https://doi.org/10.9734/BJEMT/2015/19168

Landry, A., \& Erwin, C. (2015). Perspectives on Multidisciplinary Team Processes among Healthcare Executives: Processes That Facilitate Team Effectiveness. Journal of Health and Human Services Administration, 38, 350-380.

https://www.jstor.org/stable/43948678

Lewis, S. (2015). Qualitative Inquiry and Research Design: Choosing among Five Approaches. Health Promotion Practice, 16, 473-475.

https://doi.org/10.1177/1524839915580941

Liden, R., Wayne, S., Chenwei, L., \& Meuser, J. (2014). Servant Leadership and Serving Culture: Influence on Individual and Unit Performance. Academy of Management Journal, 57, 1434-1452. https://doi.org/10.5465/amj.2013.0034

Loosemore, M., \& Bridgeman, J. (2017). Corporate Volunteering in the Construction Industry: Motivations, Costs and Benefits. Construction Management \& Economics, 35, 641-653. https://doi.org/10.1080/01446193.2017.1315150

Lorhan, S., van der Westhuizen, M., \& Gossmann, S. (2015). The Role of Volunteers at an Outpatient Cancer Center: How Do Volunteers Enhance the Patient Experience? Supportive Care in Cancer, 23, 1597-1605. https://doi.org/10.1007/s00520-014-2505-8

Manetti, G., \& Toccafondi, S. (2014). Defining the Content of Sustainability Reports in Nonprofit Organizations: Do Stakeholders Really Matter? Journal of Nonprofit \& Public Sector Marketing, 26, 35-61. https://doi.org/10.1080/10495142.2013.857498

Mauno, S., Ruokolainen, M., Kinnunen, U., \& De Bloom, J. (2016). Emotional Labour and Work Engagement among Nurses: Examining Perceived Compassion, Leadership and Work Ethic as Stress Buffers. Journal of Advanced Nursing, 72, 1169-1181. https://doi.org/10.1111/jan.12906

Mayr, M. (2017). Transformational Leadership and Volunteer Firefighter Engagement. Nonprofit Management \& Leadership, 28, 259-270. https://doi.org/10.1002/nml.21279

McBey, K., Karakowsky, L., \& Ng, P. (2017). Can I Make a Difference Here? The Impact of Perceived Organizational Support on Volunteer Commitment. Journal of Management Development, 36, 991-1007. https://doi.org/10.1108/JMD-05-2015-0078

McGeehan, L., Takehara, M., \& Daroszewski, E. (2017). Physicians' Perceptions of Volunteer Service at Safety-Net Clinics. Permanente Journal, 21, 88-96. 
https://doi.org/10.7812/TPP/16-003

Meng, H., Gull, B., Ashby, J., \& Akiko, K. (2017). The Perspectives of Non-Profit Social Service Organizations on the Value and Scope of Free Clinic Services: A Qualitative Study. Diversity \& Equality in Health \& Care, 14, 111-118. https://doi.org/10.21767/2049-5471.1000100

Muckaden, M., \& Pandya, S. (2016). Motivation of Volunteers to Work in Palliative Care Setting: A Qualitative Study. Indian Journal of Palliative Care, 22, 348-353. https://doi.org/10.4103/0973-1075.185083

Nencini, A., Romaioli, D., \& Meneghini, A. (2016). Volunteer Motivation and Organizational Climate: Factors That Promote Satisfaction and Sustained Volunteerism in NPOs. VOLUNTAS: International Journal of Voluntary \& Nonprofit Organizations, 27, 618-639. https://doi.org/10.1007/s11266-015-9593-Z

Neubert, M., Hunter, E., \& Tolentino, R. (2016). A Servant Leader and Their Stakeholders: When Does Organizational Structure Enhance a Leader's Influence? Leadership Quarterly, 27, 896-910. https://doi.org/10.1016/j.leaqua.2016.05.005

Newton, C., Becker, K., \& Bell, S. (2014). Learning and Development Opportunities as a Tool for the Retention of Volunteers: A Motivational Perspective. Human Resource Management Journal, 24, 514-530. https://doi.org/10.1111/1748-8583.12040

Noble, H., \& Smith, J. (2015). Issues of Validity and Reliability in Qualitative Research. Evidence-Based Nursing, 18, 34-35. https://doi.org/10.1136/eb-2015-102054

Northouse, P. (2016). Leadership: Theory and Practice (7th ed.). Thousand Oaks, CA: Sage.

Oostlander, J., Guntert, S., Van Schie, S., \& Wehner, T. (2014). Leadership and Volunteer Motivation: A Study Using Self-Determination Theory. Nonprofit \& Voluntary Sector Quarterly, 43, 869-886. https://doi.org/10.1177/0899764013485158

Palinkas, L., Horwitz, S., Green, C., Wisdom, J., Duan, N., \& Hoagwood, K. (2015). Purposeful Sampling for Qualitative Data Collection and Analysis in Mixed Method Implementation Research. Administration and Policy in Mental Health and Mental Health Services Research, 42, 533-544. https://doi.org/10.1007/s10488-013-0528-y

Palumbo, R. (2016). Challenging Servant Leadership in the Nonprofit Sector. Journal of Nonprofit Education and Leadership, 6, 81-98. https://doi.org/10.18666/JNEL-2016-V6-I2-6824

Paparella-Pitzel, S., Eubanks, R., \& Kaplan, S. (2016). Comparison of Teaching Strategies for Cultural Humility in Physical Therapy. Journal of Allied Health, 45, 139-146. https://pubmed.ncbi.nlm.nih.gov/27262472/

Pesut, B., Duggleby, W., Warner, G., Fassbender, K., Antifeau, E., Hooper, B. et al. (2018). Volunteer Navigation Partnerships: Piloting a Compassionate Community Approach to Early Palliative Care. BMC Palliative Care, 17, Article No. 2.

https://doi.org/10.1186/s12904-017-0210-3

Phillippi, J., \& Lauderdale, J. (2018). A Guide to Field Notes for Qualitative Research: Context and Conversation. Qualitative Health Research, 28, 381-388. https://doi.org/10.1177/1049732317697102

Posner, B. (2015). An Investigation into the Leadership Practices of Volunteer Leaders. Leadership \& Organization Development Journal, 36, 885-898. https://doi.org/10.1108/LODJ-03-2014-0061

Pozgar, G. (2016). Legal and Ethical Issues for Health Professionals (4th ed.). Burlington, MA: Jones \& Bartlett Learning. 
Pressrove, G., \& Pardun, C. (2016). Relationship between Personal Technology Use and the Donor/Volunteer: A Parasocial Approach. Journal of Promotion Management, 22, 137-150. https://doi.org/10.1080/10496491.2015.1107012

Purohit, B., Maneskar, A., \& Saxena, D. (2016). Developing a Tool to Assess Motivation among Health Service Providers Working with Public Health System in India. Human Resources for Health, 14, Article No. 15. https://doi.org/10.1186/s12960-016-0111-1

Reznickova, A., \& Zepeda, L. (2016). Can Self-Determination Theory Explain the Self-Perpetuation of Social Innovations? A Case Study of Slow Food at the University of Wisconsin-Madison. Journal of Community \& Applied Social Psychology, 26, 3-17. https://doi.org/10.1002/casp.2229

Ridder, H. (2017). The Theory Contribution of Case Study Research Designs. Business Research, 10, 281-305. https://doi.org/10.1007/s40685-017-0045-Z

Romaioli, D., Nencini, A., \& Meneghini, A. (2016). How to Foster Commitment among Volunteers: A Social Constructionist Study in Italian Nonprofit Organizations. Journal of Social Service Research, 42, 718-728. https://doi.org/10.1080/01488376.2016.1202880

Rose, G., Merchant, A., Orth, U., \& Horstmann, F. (2016). Emphasizing Brand Heritage: Does It Work? And How? Journal of Business Research, 69, 936-943. https://doi.org/10.1016/j.jbusres.2015.06.021

Rostami, P., Ashcroft, D., \& Tully, M. (2018). A Formative Evaluation of the Implementation of a Medication Safety Data Collection Tool in English Healthcare Settings: A Qualitative Interview Study Using Normalization Process Theory. PLoS ONE, 13, e0192224. https://doi.org/10.1371/journal.pone.0192224

Rowe, S., \& Alexander, N. (2015). If Trust Makes the World Go 'Round, Why Does the World Look So Flat? Nutrition Today, 50, 78-81. https://doi.org/10.1097/NT.0000000000000081

Sanford, K. (2016). The Five Questions of Physician Leadership. Frontiers of Health Services Management, 32, 39-45. https://doi.org/10.1097/01974520-201601000-00006

Scherer, L., Allen, J., \& Harp, E. (2016). Grin and Bear It: An Examination of Volunteers' Fit with Their Organization, Burnout and Spirituality. Burnout Research, 3, 1-10. https://doi.org/10.1016/j.burn.2015.10.003

Selcoe, J. (2016). Answering the Call to Service: Encouraging Volunteerism by Protecting Doctors as We Protect Ourselves. Texas Law Review, 94, 1265-1285.

https://heinonline.org/HOL/LandingPage?handle=hein.journals/tlr94\&div=45\&id=\&p age $=$

Sheehan, K. (2018). Crowdsourcing Research: Data Collection with Amazon's Mechanical Turk. Communication Monographs, 85, 140-156. https://doi.org/10.1080/03637751.2017.1342043

Sheerin, F., Stonebanks, D., Jeffery, K., \& Schouten, K. (2016). Health and Wellness in Rural Malawi: A Health Development Initiative. Primary Health Care, 26, 34-39. https://doi.org/10.7748/phc.2016.e1158

Sips, I., Haeri Mazanderani, A., Schneider, H., Greeff, M., Barten, F., \& Moshabela, M. (2014). Community Care Workers, Poor Referral Networks and Consumption of Personal Resources in Rural South Africa. PLoS ONE, 9, e95324. https://doi.org/10.1371/journal.pone.0095324

Smith, J., \& Noble, H. (2014). Bias in Research. Evidence-Based Nursing, 17, 100-101. https://doi.org/10.1136/eb-2014-101946

Solomon, I., Costea, C., \& Nita, A. (2016). Leadership versus Management in Public Or- 
ganizations. Economics, Management \& Financial Markets, 11, 143-151.

https://www.addletonacademicpublishers.com/

Soria, K., \& Thomas-Card, T. (2014). Relationships between Motivations for Community Service Participation and Desire to Continue Service Following College. Michigan Journal of Community Service Learning, 20, 53-64. https://quod.lib.umich.edu/m/mjcsl/3239521

Sousa, D. (2014). Validation in Qualitative Research: General Aspects and Specificities of the Descriptive Phenomenological Method. Qualitative Research in Psychology, 11, 211-227. https://doi.org/10.1080/14780887.2013.853855

Spender, J. (2016). Some Thoughts on Business Leadership. Revue Française De Gestion, 42, 57-69.

Starr, M. (2014). Qualitative and Mixed-Methods Research in Economics: Surprising Growth, Promising Future. Journal of Economic Surveys, 28, 238-264. https://doi.org/10.1111/joes.12004

Stukas, A., Hoye, R., Nicholson, M., Brown, K., \& Aisbett, L. (2014). Motivations to Volunteer and Their Associations with Volunteers' Well-Being. Nonprofit and Voluntary Sector Quarterly, 45, 112-132. https://doi.org/10.1177/0899764014561122

Suddaby, R. (2015). Editor's Comments: Why Theory? Academy of Management Review, 39, 407-411. https://doi.org/10.5465/amr.2014.0252

Sudha, K., Shahnawaz, M., \& Farhat, A. (2016). Leadership Styles, Leader's Effectiveness and Well-Being: Exploring Collective Efficacy as a Mediator. Vision, 20, 111-120. https://doi.org/10.1177/0972262916637260

Swensen, S., Gorringe, G., Caviness, J., \& Peters, D. (2016). Leadership by Design: Intentional Organization Development of Physician Leaders. Journal of Management Development, 35, 549-570. https://doi.org/10.1108/JMD-08-2014-0080

Tang, F. (2016). Retirement Patterns and Their Relationship to Volunteering. Nonprofit \& Voluntary Sector Quarterly, 45, 910-930. https://doi.org/10.1177/0899764015602128

Thomas, D. (2017). Feedback from Research Participants: Are Member Checks Useful in Qualitative Research? Qualitative Research in Psychology, 14, 23-41. https://doi.org/10.1080/14780887.2016.1219435

Toader, E. (2014). The Effects of Rising Healthcare Costs on the US Economy. American Journal of Medical Research, 1, 44-50. https://www.ceeol.com/search/journal-detail?id=2184

Tran, V. T., Porcher, R., Tran, V. S., \& Ravaud, P. (2017). Predicting Data Saturation in Qualitative Surveys with Mathematical Models from Ecological Research. Journal of Clinical Epidemiology, 82, 71-78.E2. https://doi.org/10.1016/j.jclinepi.2016.10.001

Tsai, T., \& Lin, A. (2014). Do Psychological Contract and Organizational Citizenship Behavior Affect Organizational Performance in Non-Profit Organizations? Chinese Management Studies, 8, 397-417. https://doi.org/10.1108/CMS-05-2013-0090

Tung, F. (2016). Does Transformational, Ambidextrous, Transactional Leadership Promote Employee Creativity? Mediating Effects of Empowerment and Promotion Focus. International Journal of Manpower, 37, 1250-1263. https://doi.org/10.1108/IJM-09-2014-0177

Ugwu, F., Onyishi, I., \& Rodríguez-Sánchez, A. (2014). Linking Organizational Trust with Employee Engagement: The Role of Psychological Empowerment. Personnel Review, 43, 377-400. https://doi.org/10.1108/PR-11-2012-0198

Valeau, P. (2015). Stages and Pathways of Development of Nonprofit Organizations: An 
Integrative Model. VOLUNTAS: International Journal of Voluntary and Nonprofit Organizations, 26, 1894-1919. https://doi.org/10.1007/s11266-014-9501-y

Valero, J., Jung, K., \& Andrew, S. (2015). Does Transformational Leadership Build Resilient Public and Nonprofit Organizations? Disaster Prevention \& Management, 24, 4-20. https://doi.org/10.1108/DPM-04-2014-0060

Van den Berg, A., \& Struwig, M. (2017). Guidelines for Researchers Using an Adapted Consensual Qualitative Research Approach in Management Research. Electronic Journal of Business Research Methods, 15, 109-119.

https://wwww.ejbrm.com/

Van der Walt, F., \& Swanepoel, H. (2015). The Relationship between Workplace Spirituality and Job Involvement: A South African Study. African Journal of Business \& Economic Research, 10, 95-116. https://journals.co.za/

Van Schie, S., Guntert, S., \& Wehner, T. (2014). How Dare to Demand This from Volunteers! The Impact of Illegitimate Tasks. VOLUNTAS: International Journal of Voluntary and Nonprofit Organizations, 25, 851-868. https://doi.org/10.1007/s11266-013-9375-4

Van Winkle, B., Allen, S., De Vore, D., \& Winston, B. (2014). The Relationship between the Servant Leadership Behaviors of Immediate Supervisors and Followers' Perceptions of Being Empowered in the Context of Small Business. Journal of Leadership Education, 13, 70-82. https://doi.org/10.12806/V13/I3/R5

Vareilles, G., Pommier, J., Marchal, B., \& Kane, S. (2017). Understanding the Performance of Community Health Volunteers Involved in the Delivery of Health Programmes in Underserved Areas: A Realist Synthesis. Implementation Science, 12, Article No. 22. https://doi.org/10.1186/s13012-017-0554-3

Varpio, L., Ajjawi, R., Monrouxe, L., O’Brien, B., \& Rees, C. (2017). Shedding the Cobra Effect: Problematising Thematic Emergence, Triangulation, Saturation and Member Checking. Medical Education, 51, 40-50. https://doi.org/10.1111/medu.13124

Vaughn, P., \& Turner, C. (2016). Decoding via Coding: Analyzing Qualitative Text Data through Thematic Coding and Survey Methodologies. Journal of Library Administration, 56, 41-51. https://doi.org/10.1080/01930826.2015.1105035

Walker, A., Accadia, R., \& Costa, B. (2016). Volunteer Retention: The Importance of Organisational Support and Psychological Contract Breach. Journal of Community Psychology, 44, 1059-1069. https://doi.org/10.1002/jcop.21827

Waters, R., \& Bortree, D. (2012). Improving Volunteer Retention Efforts in Public Library Systems: How Communication and Inclusion Impact Female and Male Volunteers Differently. International Journal of Nonprofit \& Voluntary Sector Marketing, 17, 92-107. https://doi.org/10.1002/nvsm.438

Wellens, L., \& Jegers, M. (2014). Effective Governance in Nonprofit Organizations: A Literature Based Multiple Stakeholder Approach. European Management Journal, 32, 223-243. https://doi.org/10.1016/j.emj.2013.01.007

Whiteoak, J., \& Mohamed, S. (2016). Employee Engagement, Boredom and Frontline Construction Workers Feeling Safe in Their Workplace. Accident Analysis \& Prevention, 93, 291-298. https://doi.org/10.1016/j.aap.2015.11.001

Wieland, A., Handfield, R., \& Durach, C. (2016). Mapping the Landscape of Future Research Themes in Supply Chain Management. Journal of Business Logistics, 37, 205-212. https://doi.org/10.1111/jbl.12131

Wolgemuth, J., Hicks, T., \& Agosto, V. (2017). Unpacking Assumptions in Research Synthesis: A Critical Construct Synthesis Approach. Educational Researcher, 46, 
131-139. https://doi.org/10.3102/0013189X17703946

Wolin, R. (2016). Unrealistic Goals and Organizational Pressures That Can Lead to Compliance Failure. Journal of Health Care Compliance, 18, 55-56.

https://lrus.wolterskluwer.com/store/product/journal-of-health-care-compliance

Wu, Y., Li, C., \& Khoo, S. (2016). Predicting Future Volunteering Intentions through a Self-Determination Theory Perspective. VOLUNTAS: International Journal of Voluntary \& Nonprofit Organizations, 27, 1266-1279.

https://doi.org/10.1007/s11266-015-9570-6

Yamashita, T., López, E., Soligo, M., \& Keene, J. (2017). Older Lifelong Learners' Motivations for Participating in Formal Volunteer Activities in Urban Communities. Adult Education Quarterly, 67, 118-135. https://doi.org/10.1177/0741713616688957

Yates, J., \& Leggett, T. (2016). Qualitative Research: An Introduction. Radiologic Technology, 88, 225-231. https://pubmed.ncbi.nlm.nih.gov/27837140

Yin, R. (2018). Case Study Research and Applications: Design and Methods (6th ed.). Thousand Oaks, CA: Sage.

York, P. (2017). Effective Volunteer Engagement for Sustainability and Growth. Journal of Nonprofit Education \& Leadership, 7, 32-38.

https://doi.org/10.18666/JNEL-2017-V7-I1-8024

Zapata, Cantu, L., \& Mondragon, C. (2016). Knowledge Management in Mexican NPOs: A Comparative Study in Organizations with a Local and National Presence. Journal of Knowledge Management, 20, 69-87. https://doi.org/10.1108/JKM-12-2014-0494 